\title{
Polymorphic Copper Iodide Anions: Luminescence Thermochromism and Mechanochromism of
} $\left(\mathrm{PPh}_{4}\right)_{2}\left[\mathrm{Cu}_{2} \mathrm{I}_{4}\right]$

\author{
Yaouen Thefioux, ${ }^{a}$ Marie Cordier, ${ }^{b}$ Florian Massuyeau, ${ }^{a}$ Camille Latouche, ${ }^{a}$ Charlotte \\ Martineau-Corcos, ${ }^{c, d}$ and Sandrine Perruchas ${ }^{a *}$
}

\begin{abstract}
${ }^{a}$ Université de Nantes, CNRS, Institut des Matériaux Jean Rouxel, IMN, F-44000 Nantes, France. Phone: (+33) (0)2 403763 35. E-mail: sandrine.perruchas@cnrs-imn.fr

${ }^{\mathrm{b}}$ Université de Rennes, CNRS, ISCR (Institut des Sciences Chimiques de Rennes), UMR 6226, F-35000 Rennes, France.
\end{abstract}

${ }^{\mathrm{c}}$ MIM, Institut Lavoisier de Versailles (ILV), UMR CNRS 8180, Université de Versailles St-Quentin en Yvelines (UVSQ), 45, avenue des Etats-Unis, 78035 Versailles Cedex, France.

${ }^{\mathrm{d}}$ CNRS, CEMHTI UPR 3079, Université d'Orléans, F-45071 Orléans, France.

\begin{abstract}
The photoluminescent stimuli-responsive properties of two crystalline polymorphs of $\left(\mathrm{PPh}_{4}\right)_{2}\left[\mathrm{Cu}_{2} \mathrm{I}_{4}\right]$ formula, are reported. Distinct luminescence properties are exhibited by these ionic copper iodide compounds with blue or yellow emission and original luminescence thermochromism and mechanochromism are demonstrated. While one polymorph displays contrasted temperature-dependent emission properties, the other shows great modification of its emission upon mechanical solicitation. Establishment of structure-properties relationships supported by theoretical approach, permit to get insights into the origin of the photoluminescence properties and the mechanisms at play. According to DFT calculations, the different emission bands originate either from the $\left(\mathrm{PPh}_{4}\right)^{+}$organic cation or from the $\left[\mathrm{Cu}_{2} \mathrm{I}_{4}\right]^{2-}$ anion. Activation of these two emissive centers appears to be dependent on the crystalline packing of the polymorph. The thermochromism displayed by one polymorph can be attributed to variation in temperature of the relative intensities of two emission bands of two different excited states. The origin is different for the other polymorph with emission bands coming from two independent emissive centers namely, $\left(\mathrm{PPh}_{4}\right)^{+}$and $\left[\mathrm{Cu}_{2} \mathrm{I}_{4}\right]^{2-}$. The luminescence mechanochromism is attributed to a polymorphic transition. The mechanical solicitation induces a partial transformation of one polymorph into the other within a disordered phase. The mechanochromic mechanism can be related to mechanical modifications of inter-molecular interactions between the $\left(\mathrm{PPh}_{4}\right)^{+}$cations. By displaying luminescence properties that dependent on crystalline structure, excitation wavelength, temperature and mechanical solicitation, the studied copper iodides offer a great possibility of emissive color control and switch, a clear demonstration of great potentialities of this family of compounds for developing photoactive materials.
\end{abstract}




\section{Introduction.}

Luminescent materials exhibiting multicolor emission switching are attracting attention due to their potential applications in data storage devices and security systems, for instance. ${ }^{1,2}$ Because of their outstanding photophysical properties and economic advantages, copper complexes are particularly appealing for developing light-emitting functional materials. ${ }^{3,4,5,67,8}$ Amongst $\mathrm{Cu}$-based compounds, copper(I) iodide derivatives have recently emerged as attractive emissive materials due to their rich optical properties. ${ }^{9,10,11,12,13}$

The $\mathrm{d}^{10}$ electronic configuration of $\mathrm{Cu}(\mathrm{I})$ gives rise to diverse coordination number/geometries and associated to the multiple connectivity modes of halides, the family of copper iodides present a great structural diversity, leading consequently to various photophysical properties. Actually, their potential applications as sensors, ${ }^{14,15,16,17}$ photocatalytic systems, ${ }^{18}$ and emitters in organic light-emitting diodes (OLEDs), ${ }^{19,20,21,22,23}$ have been recently reported. Copper(I) iodide compounds can also display diverse stimuli-responsive properties such as luminescence thermochromism, ${ }^{24,25}$ mechanochromism, ${ }^{26,27}$ rigidochromism, ${ }^{28}$ or vapo/solvatochromism. ${ }^{29}$ Combining multistimuli-responsive properties is actually particularly appealing to access original multifunctional materials. The molecular cubane clusters formulated $\left[\mathrm{Cu}_{4} \mathrm{I}_{4} \mathrm{~L}_{4}\right]$ ( $\mathrm{L}=$ ligand) is indeed well known for exhibiting multistimuli-responsive properties that are closely related to metallophilic interactions. Within the family of neutral copper iodides, another iconic complex is the rhomboid one formulated $\left[\mathrm{Cu}_{2} \mathrm{I}_{2} \mathrm{~L}_{2}\right] \cdot{ }^{19,30,31}$ While its emissive properties have been well described, its stimuli-responsive properties remain rare. ${ }^{27 a}$ Although fewer compared with neutral derivatives, charged copper iodide complexes are documented whose structural geometry vary with the counter-ion. ${ }^{13}$ Common anions are the binuclear $\left[\mathrm{Cu}_{2} \mathrm{I}_{6}\right]^{4-}$ and the tetranuclear $\left[\mathrm{Cu}_{4} \mathrm{I}_{8}\right]^{4-32}$ ones for which iodides replace the organic ligands, present in the neutral complexes. Note that zwitterionic compounds which covalently bind the anion and cation, have been recently reported. ${ }^{33}$ Another binuclear anion is $\left[\mathrm{Cu}_{2} \mathrm{I}_{4}\right]^{2-}$ which has been encountered in several associations with different organic and inorganic cations. ${ }^{34,35,36,37,38,39,40,41,42,43,44,45,46,47,48,49,50,51,52,53,54,55,56,57,58,59,60,61,62,63,64,65,66}$ The photophysical properties of these compounds have been rarely characterized, $\left[\mathrm{Cu}_{2} \mathrm{I}_{4}\right]^{2-}$ being simply treated as an inorganic counter-anion and not as an emissive species by itself. In particular, with the tetraphenylphosphonium cation, the polymorphic structure of $\left(\mathrm{PPh}_{4}\right)_{2}\left[\mathrm{Cu}_{2} \mathrm{I}_{4}\right]$ has been reported but no photophysical characterization has been investigated. ${ }^{67,68}$ Occurrence of crystalline polymorphism provides a great tool to explore structure-properties relationships of molecular solids and to get insights into their physical properties. ${ }^{69}$ In particular, crystalline polymorphs of luminescent compounds usually exhibit different photophysical properties allowing determining the mechanisms at the origin of their light-emitting properties and even stimuli-responsive ones. This opportunity motivated our investigations for exploring the photophysical properties of the $\left(\mathrm{PPh}_{4}\right)_{2}\left[\mathrm{Cu}_{2} \mathrm{I}_{4}\right]$ compounds.

Here, we report on the stimuli-responsive properties of two crystalline polymorphs of $\left(\mathrm{PPh}_{4}\right)_{2}\left[\mathrm{Cu}_{2} \mathrm{I}_{4}\right]$ resulting from the association of the $\left[\mathrm{Cu}_{2} \mathrm{I}_{4}\right]^{2-}$ anion and the $\left(\mathrm{PPh}_{4}\right)^{+}$cation (Figure 1). Original luminescence thermochromism and mechanochromism are demonstrated for these compounds. Comparative structural and photophysical characterisations of the two polymorphs are presented in order to elucidate the mechanochromism mechanism at play. Theoretical studies have been also conducted aiming at rationalizing the experimental light-emitting properties. 


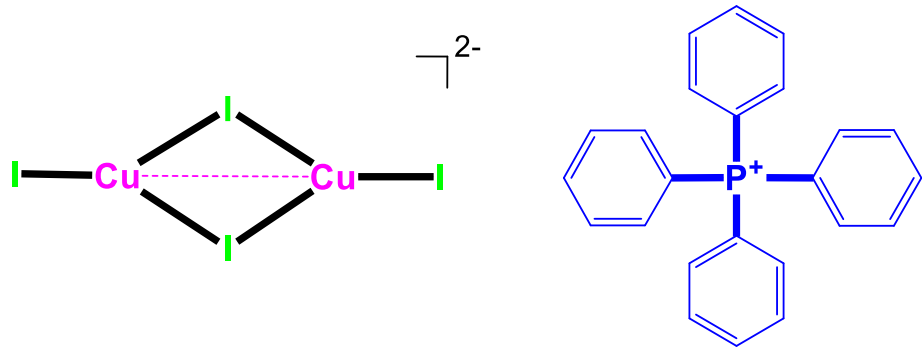

Figure 1. Schematic drawing of the $\left[\mathrm{Cu}_{2} \mathrm{I}_{4}\right]^{2-}$ anion and $\left(\mathrm{PPh}_{4}\right)^{+}$cation.

\section{Results and Discussions.}

The two crystalline polymorphs of $\left(\mathbf{P P h}_{4}\right)_{2}\left[\mathbf{C u}_{2} \mathbf{I}_{4}\right]$, namely $\mathbf{A}$ and $\mathbf{B}$, were synthesized in solution by reacting copper iodide $(\mathrm{CuI})$ and tetraphenylphosphonium iodide $\left.\left(\mathrm{P}^{(} \mathrm{C}_{6} \mathrm{H}_{4}\right)_{4} \mathrm{I}\right)$ in dichloromethane, acetone or acetonitrile, at room temperature (details in experimental section). By slowly adding an antisolvent (diethyl-ether or cyclohexane) to the reaction solution, the products precipitated as colorless crystalline powders. Both polymorphs are formed concomitantly but their relative proportion vary with the nature of the used solvents. For the dichloromethane/cyclohexane solvents, polymorph $\mathbf{A}$ is largely predominant but for the acetonitrile/diethyl-ether combination this is the polymorph $\mathbf{B}$. Rapid concentration of an acetone solution leads exclusively to polymorph $\mathbf{B}$. The $\left(\mathrm{PPh}_{4}\right)_{2}\left[\mathrm{Cu}_{2} \mathrm{I}_{4}\right]$ formula is in agreement with elemental analysis (experimental section). The reported synthesis for these two polymorphs ( $\mathbf{A}$ and $\mathbf{B}$ ), uses $\mathrm{Cu}, \mathrm{I}_{2}$ and $\mathrm{PPh}_{4} \mathrm{I}$ as reactants in acetone. Concomitant formation was also reported in this previous work. ${ }^{67}$ The synthesis of two other known polymorphs namely $\left(\mathbf{P P h}_{4}\right)_{2}\left[\mathbf{C u}_{2} \mathbf{I}_{4}\right]-$ $\mathbf{C}$ and $\mathbf{D}$ was also described with acetone as solvent with $\mathrm{Cu}, \mathrm{I}_{2}$ and $\mathrm{PPh}_{4} \mathrm{I}$ as reactants. ${ }^{68}$ None of these two latter were obtained in our synthesis conditions.

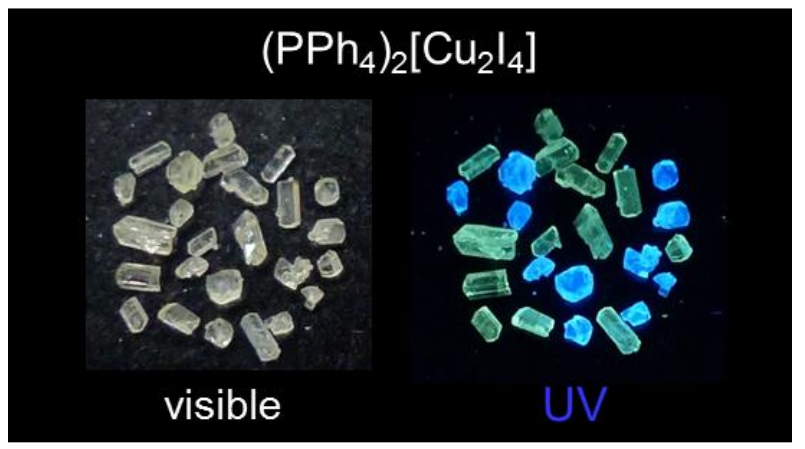

Figure 2. Photos of the crystalline polymorphs $\left(\mathbf{P P h}_{4}\right)_{2}\left[\mathbf{C u}_{2} \mathbf{I}_{4}\right]$ under ambient light and under UV irradiation (lamp at $365 \mathrm{~nm}$ ) with the yellow-emitting $\mathbf{A}$ and blue-emitting $\mathbf{B}$, at room temperature.

The colorless crystals of the two polymorphs exhibit distinctive emission colors under UV irradiation, with a yellow emission for $\mathbf{A}$ while that of $\mathbf{B}$ is blue (Figure 2). Real crystalline polymorphs displaying such different emission properties in the visible spectra are quite rare. Their respective crystal structures were determined by SCXRD (single crystal X-Ray diffraction) analysis at different temperatures (100, 150,200 and $293 \mathrm{~K}$, Table S1). Their structures were already solved ${ }^{67}$ at room temperature but here are reported low temperature measurements to correlate with the photoluminescence data. The purity of the 
samples was confirmed by powder X-ray diffraction analysis (Figure S3) and elemental analysis (experimental part in SI). $\mathbf{A}$ and $\mathbf{B}$ crystallize in the monoclinic $P 2_{1} / \mathrm{c}$ space group. The unit cell contents are shown in Figure 3. Both structures can be described as an alternation of organic layers formed by the $\mathrm{PPh}_{4}{ }^{+}$cations and inorganic layers formed by the $\left[\mathrm{Cu}_{2} \mathrm{I}_{4}\right]^{2-}$ anions. No solvent of crystallization is included in the structures giving to these two compounds the important characteristic of real crystalline polymorphs. Indeed, the comparative study is in this case straightforward and not hampered by the potential effect of solvent of crystallization.
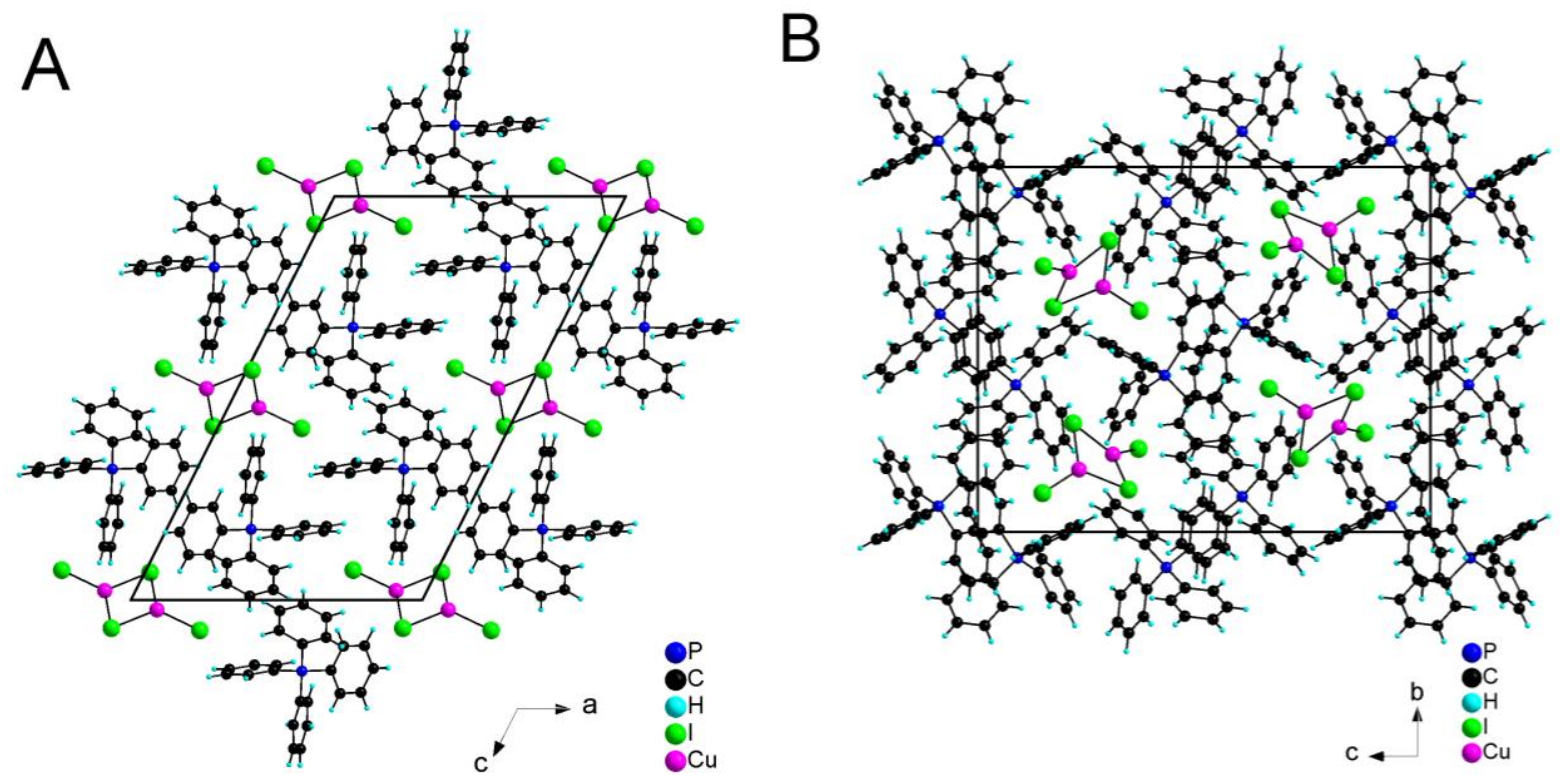

Figure 3. View of the unit cell of $\left(\mathbf{P P h}_{4}\right)_{2}\left[\mathbf{C u}_{2} \mathbf{I}_{4}\right]-\mathbf{A}$ and $\mathbf{B}$ polymorphs at $293 \mathrm{~K}$.

The $\left(\mathrm{PPh}_{4}\right)^{+}$cation in $\mathbf{A}$ and the two independent ones in $\mathbf{B}$, present a classical geometry with a tetrahedral environment around the phosphorus atom. Free rotation around the P-C bond leads to different orientation of the phenyl groups (Figure $\mathrm{S} 1$ ). The molecular structure of the $\left[\mathrm{Cu}_{2} \mathrm{I}_{4}\right]^{2-}$ anions are depicted in Figure 4. All $\mathrm{Cu}$ atoms present a pseudo-trigonal $\mathrm{CuI}_{3}$ environment with iodide atoms in $\mu_{1}$ and $\mu_{2}$ coordination modes. In polymorph $\mathbf{A},\left[\mathrm{Cu}_{2} \mathbf{I}_{4}\right]^{2-}$ has an inversion center whereas in $\mathbf{B}$ it is in general position. Selected bond lengths and angles in the $\left[\mathrm{Cu}_{2} \mathrm{I}_{4}\right]^{2-}$ anions at $293 \mathrm{~K}$ are listed in Table 1. The $\mathrm{Cu}-\mathrm{I}$ bond distances and I-Cu-I angle values are within the range of reported values for such copper iodide compounds. ${ }^{34-66}$ The $\mathrm{Cu}-\mathrm{I} \mu_{1}$-bond distances are shorter than the $\mathrm{Cu}-\mathrm{I} \mu_{2}$ ones in agreement with the stronger ionic interaction. The intramolecular $\mathrm{Cu}-\mathrm{Cu}$ bond distances in $\mathbf{A}\left(\mathrm{Cu}_{1}-\mathrm{Cu}_{1}=2.955(1) \AA\right)$ is much longer compared with that in $\mathbf{B}\left(\mathrm{Cu}_{1}-\mathrm{Cu}_{2}=2.662(1) \AA\right.$ at $\left.293 \mathrm{~K}\right)$. These $\mathrm{Cu}-\mathrm{Cu}$ distances lie in the range of values encountered in copper iodide compounds. ${ }^{9,13,26}$ Nevertheless comparison with the value of the sum of the van der Waals radii of $\mathrm{Cu}$ of $2.80 \AA$, suggests that strong cuprophilic bonding interaction $\left(\mathrm{d}^{10}-\mathrm{d}^{10}\right)$ occurs in $\mathbf{B}$, whereas it is much weaker in the case of $\mathbf{A}^{70,71}$ Values of the torsional angles in the $\left[\mathrm{Cu}_{2} \mathrm{I}_{4}\right]^{2-}$ anions are significantly different in the two polymorphs (mean values of 173.86(4) in $\mathbf{A}$ and $162.07(4)^{\circ}$ in $\mathbf{B}$ ), as reported in Table 1. As shown in Figure 4, these geometric differences lead in $\mathbf{A}$ to an almost planar form of the $\left[\mathrm{Cu}_{2} \mathrm{I}_{4}\right]^{2-}$ anion and to a strongly folded one in $\mathbf{B}$. Bond lengths and angles in the $\left[\mathrm{Cu}_{2} \mathrm{I}_{4}\right]^{2-}$ anions at lower temperatures are reported in Table 1 (100 and $\left.293 \mathrm{~K}\right)$ and S3 
(100, 150, 200 and $293 \mathrm{~K})$. Similar temperature dependent behavior is observed for both polymorphs with crystal lattice contraction (from 293 to $100 \mathrm{~K}$ ) of 2.3 and $3.0 \%$ in $\mathbf{A}$ and $\mathbf{B}$, respectively. The $\mathbf{C u}-$ $\mathrm{Cu}$ distances present a shortening upon temperature decreasing of 3.0 and $2.1 \%$ in $\mathbf{A}$ and $\mathbf{B}$, respectively. Concerning the $\mathrm{Cu}-\mathrm{I}$ bond distances (mean values), slight increases of $0.2 \%$ for $\mathbf{A}$ and $0.1 \%$ for $\mathbf{B}$ are observed by lowering the temperature. These observations mean that upon decreasing the temperature, the $\mathrm{Cu}-\mathrm{Cu}$ distances contract while $\mathrm{Cu}-\mathrm{I}$ ones remain almost constant. This can be explained by the $\mathrm{Cu}$ $\mathrm{Cu}$ interactions of $\mathrm{d}^{10}-\mathrm{d}^{10}$ type which are weaker compared with the ionic $\mathrm{Cu}-\mathrm{I}$ bonds and their modification minimizes the crystal packing energy. This phenomena has been already observed in copper iodide clusters by applying isostatic pressure. ${ }^{72}$ Even if the thermal lattice contraction is larger in $\mathbf{B}$ compared with that of $\mathbf{A}$, this is the $\left[\mathrm{Cu}_{2} \mathrm{I}_{4}\right]^{2-}$ anion in $\mathbf{A}$ that presents the more important structural changes. This can be due to the longer $\mathrm{Cu}-\mathrm{Cu}$ distances in $\mathbf{A}$ that is far from the van der Waals value, being therefore more easily compressible. The density can be a criteria to evaluate the relative stability of crystalline polymorphs, with more stable compounds having denser phase. ${ }^{69}$ However, the very close density values of $\mathbf{A}$ and $\mathbf{B}$ (1.863 and 1.851 respectively at $293 \mathrm{~K}$ ) does not give useful information in the present case.
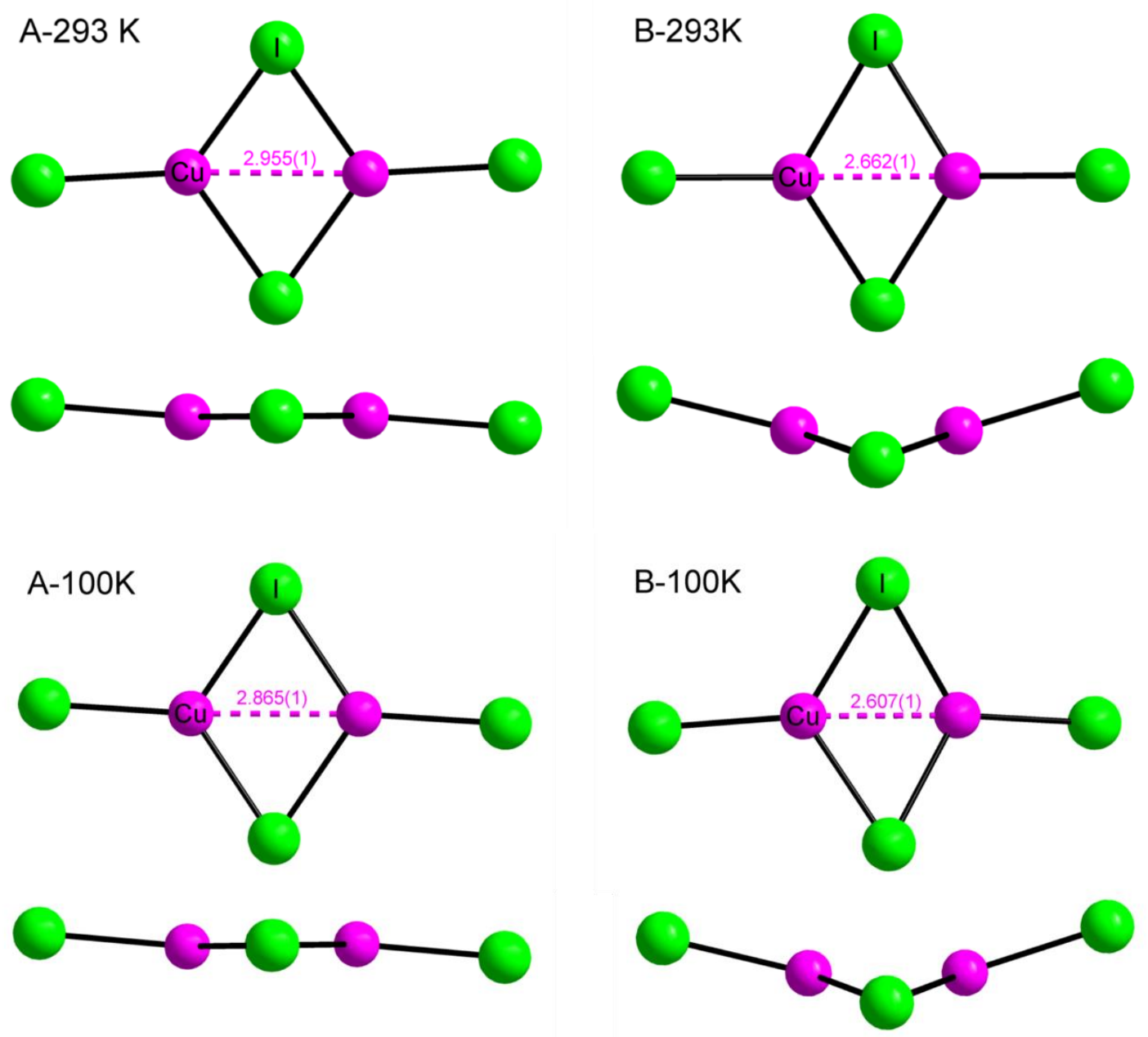

Figure 4. Molecular structure of $\left[\mathrm{Cu}_{2} \mathrm{I}_{4}\right]^{2-}$ anion in $\left(\mathbf{P P h}_{4}\right)_{2}\left[\mathbf{C u}_{2} \mathbf{I}_{4}\right]-\mathbf{A}$ and $\mathbf{B}$ polymorphs at 293 and $100 \mathrm{~K}$. 
Table 1. Selected intramolecular bonds lengths and angles of $(\mathbf{P P h})_{2}\left[\mathbf{C u}_{2} \mathbf{I}_{4}\right]$ at 100 and $293 \mathrm{~K}$ from SCXRD.

\begin{tabular}{|c|c|c|c|c|}
\hline \multirow[t]{2}{*}{ Compound } & \multicolumn{2}{|c|}{$\mathbf{A}$} & \multicolumn{2}{|c|}{ B } \\
\hline & $100 \mathrm{~K}$ & $293 \mathrm{~K}$ & $100 \mathrm{~K}$ & $293 \mathrm{~K}$ \\
\hline $\mathrm{Cu} \cdots \mathrm{Cu}$ & $2.8652(9)$ & $2.9549(13)$ & $2.6072(5)$ & $2.6621(9)$ \\
\hline $\begin{array}{c}\mathbf{C u}-\mathbf{I} \boldsymbol{\mu}_{\mathbf{1}} \\
\text { mean }\end{array}$ & $\begin{array}{l}2.5833(6) * 2 \\
2.5907(6) * 2 \\
2.5126(7) * 2 \\
2.5622(7)\end{array}$ & $\begin{array}{l}2.5806(7) * 2 \\
2.5932(7) * 2 \\
2.4954(7) * 2 \\
2.5564(7)\end{array}$ & $\begin{array}{l}2.5711(5) \\
2.5740(4) \\
2.6033(4) \\
2.6076(5) \\
2.4969(4) \\
2.4976(4) \\
2.5584(5)\end{array}$ & $\begin{array}{l}2.5720(8) \\
2.5780(8) \\
2.6029(8) \\
2.6086(7) \\
2.4858(7) \\
2.4904(7) \\
2.5563(8)\end{array}$ \\
\hline $\mathrm{I} \mu_{2}-\mathrm{Cu}-\mathrm{I} \boldsymbol{\mu}_{2}$ & $\begin{array}{l}125.87(2) * 2 \\
120.98(2) * 2 \\
112.75(2) * 2\end{array}$ & $\begin{array}{l}127.09(3) * 2 \\
122.26(3) * 2 \\
110.34(2) * 2\end{array}$ & $\begin{array}{l}125.19(2) \\
119.92(2) \\
124.57(2) \\
119.99(2) \\
114.80(1) \\
114.85(2)\end{array}$ & $\begin{array}{l}124.71(3) \\
121.27(3) \\
124.58(3) \\
121.12(3) \\
113.94(3) \\
113.93(3)\end{array}$ \\
\hline I-Cu-I-Cu & $\begin{array}{l}172.76(3) * 2 \\
173.16(3) * 2\end{array}$ & $\begin{array}{l}173.68(4) * 2 \\
174.04(4) * 2\end{array}$ & $\begin{array}{l}159.14(3) \\
159.27(3) \\
164.21(3) \\
164.51(3)\end{array}$ & $\begin{array}{l}160.15(4) \\
160.22(4) \\
163.89(4) \\
164.00(4)\end{array}$ \\
\hline
\end{tabular}

The great majority of the reported compounds incorporating the $\left[\mathrm{Cu}_{2} \mathrm{I}_{4}\right]^{2-}$ anion present a planar geometry. In addition to the case of $\left(\mathrm{PPh}_{4}\right)_{2}\left[\mathrm{Cu}_{2} \mathrm{I}_{4}\right],{ }^{67,68}$ only three examples of $\left[\mathrm{Cu}_{2} \mathrm{I}_{4}\right]^{2-}$ anion with a folded geometry are known, with the $\mathrm{As}\left(\mathrm{Ph}_{4}\right)^{+40},\left(\mathrm{CH}_{3} \mathrm{PPh}_{3}\right)^{+45}$, and $\mathrm{Ba}$ (tetraglyme $)_{2}{ }^{2+39}$ cations. The spherical geometry of these three cations may account for structural constraints leading to the folded geometry. This reflects the flexibility of copper(I) halide complexes that can adapt their molecular geometry to the crystalline packing. Regarding the $\mathrm{Cu}-\mathrm{Cu}$ distances, the values with the $\mathrm{As}_{(}\left(\mathrm{Ph}_{4}\right)^{+},{ }^{40}$ $\left(\mathrm{CH}_{3} \mathrm{PPh}_{3}\right)^{+},{ }^{45}$ and $\mathrm{Ba}$ (tetraglyme $)_{2}{ }^{2+}{ }^{39}$ cations are 2.663(4), 2.678(3) and 2.636(1) $\AA$, respectively, which are similar to that of $\mathbf{B}(2.662(1) \AA)$. They indeed all lie within the range of 2.6-2.8 $\AA$ of the literature values. The relatively long value of 2.955(1) $\AA$ found in $\mathbf{A}$, can be associated to its planar geometry. Indeed, the planar $\left[\mathrm{Cu}_{2} \mathrm{I}_{4}\right]^{2-}$ anion with comparable $\mathrm{Cu}-\mathrm{Cu}$ distance of 2.938(1) $\AA$ has been reported with a phosphonium anion $\left(i-\operatorname{Pr}\left(\mathrm{Ph}_{3} \mathrm{P}\right)\right)^{+}{ }^{34}$

Short intermolecular contacts $\left(<3 \AA\right.$ ) are present in the crystalline structure of A and B. Several C- $\mathrm{H}^{\cdots \cdots} \mathbf{C}$ contacts occur between the phenyl groups of the phosphonium cations (2.897(1), 2.911(1) and 2.914(1) $\AA$ in $\mathbf{A}$ and 2.928(1), 2.949(1), 2.922(1) and 2.854(1) $\AA$ in $\mathbf{B}) . \mathrm{Cu}^{\cdots} \mathrm{H}$ contacts also exist in $\mathbf{A}$ of 2.631(1) $\AA$ whereas the shortest one in $\mathbf{B}$ is of 2.938(1) $\AA$ (Figure S2). As shown in Figure 5, $\pi$ - $\pi$ stacking can be also observed in A with $\mathbf{C}^{\cdots} \mathbf{C}$ contacts of 3.398(1) and 3.950(1) $\AA$. Such interaction is not found in $\mathbf{B}$. The different networks of interactions between the phenyl groups in $\mathbf{A}$ and $\mathbf{B}$ are confirmed by the different FTIR signatures around $3050 \mathrm{~cm}^{-1}$ (Figure S4). 


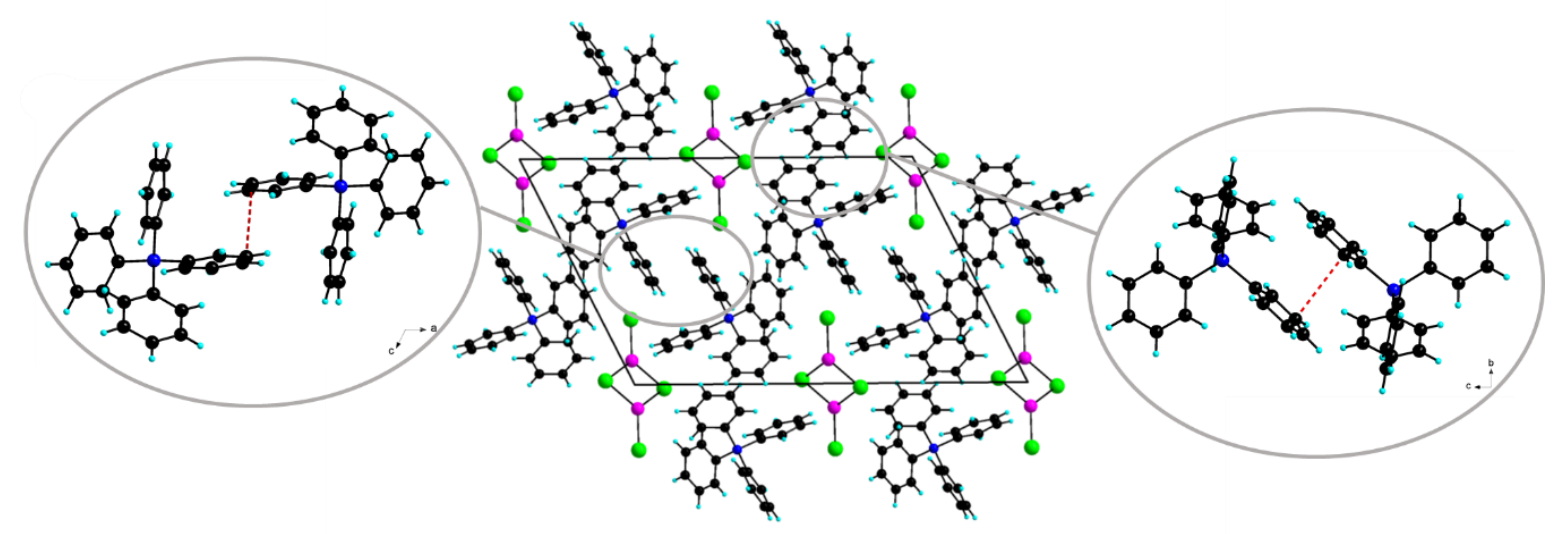

Figure 5. Intermolecular $\pi-\pi$ interactions in $\left(\mathbf{P P h}_{4}\right)_{2}\left[\mathbf{C u}_{2} \mathbf{I}_{4}\right]-\mathbf{A}$.

Structural comparison with the two other known polymorphs, $\mathbf{C}$ and $\mathbf{D},{ }^{68}$ indicates similarities between $\mathbf{A}$ and $\mathbf{C}$ and, $\mathbf{B}$ and $\mathbf{D}$. $\left[\mathrm{Cu}_{2} \mathrm{I}_{4}\right]^{2-}$ anion presents a planar geometry in $\mathbf{C}$ as observed in $\mathbf{A}$ and a similar close packing of $\left(\mathrm{PPh}_{4}\right)+$ cations is found in these two polymorphs. In $\mathbf{D}$, the geometry of the $\left[\mathrm{Cu}_{2} \mathrm{I}_{4}\right]^{2-}$ anion is folded as in $\mathbf{B}$. These polymorphs however present different arrangements of the $\left(\mathrm{PPh}_{4}\right)+$ cations that are less dense compared with that of $\mathbf{A}$ and $\mathbf{C}$.

Luminescent mechanochromism is exhibited by polymorph $\mathbf{B}$ whereas no emission modification was observed for A under mechanical solicitation. As shown in Figure 6, the manual grinding of crystalline powder of $\mathbf{B}$ results in a great emission change by shifting from blue to yellow light. Meanwhile, the ground phase, noted $\mathbf{B} \boldsymbol{g}$ ( $g$ stands for ground), maintains the slightly yellowish bodycolor of the initial crystalline sample. To our knowledge, $\mathbf{B}$ is the only example of CuI-based mechanochromic compounds of ionic nature. Note that mechanosynthesis was tested to synthesize $\left(\mathrm{PPh}_{4}\right)_{2}\left[\mathrm{Cu}_{2} \mathrm{I}_{4}\right]$ by grinding the reactants with drops of solvent. This was unsuccessful to obtain polymorph A but from PXRD analysis, polymorph B was detected. After careful examination, polymorph $\mathbf{B}$ was not obtained but the ground form $\mathbf{B} \boldsymbol{g}$ instead. The mechanosynthesis has therefore to be employed carefully when mechanochromic compounds are involved.

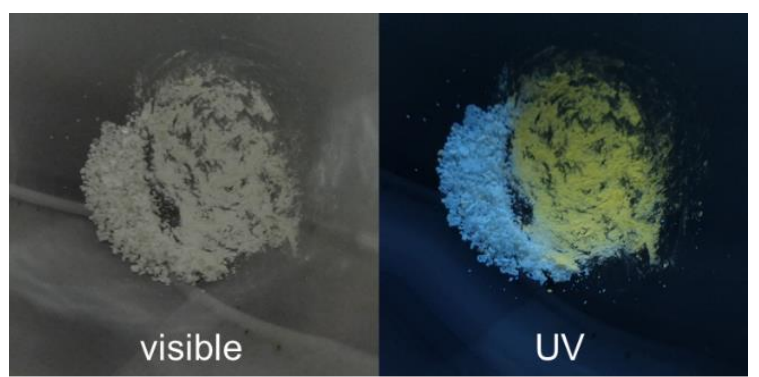

Figure 6. Photos of crystalline powder of $\left(\mathrm{PPh}_{4}\right)_{2}\left[\mathrm{Cu}_{2} \mathbf{I}_{4}\right]-\mathrm{B}$ partially ground (right side) under visible light and UV irradiation (365 nm UV lamp), at room temperature.

Results of elemental analysis of $\mathbf{B g}$ are similar to those of $\mathbf{B}$ corresponding to the $\left(\mathbf{P P h}_{4}\right)_{2}\left[\mathbf{C u}_{2} \mathbf{I}_{4}\right]$ formula (experimental section), indicating that no chemical reaction related to adsorption or removal of atmospheric molecules are induced by the grinding process. Solid state ${ }^{31} \mathrm{P}$ NMR analysis (vide infra) also demonstrates that the molecular structure of the complex is preserved in Bg. The powder X-Ray 
diffraction (PXRD) analysis of $\mathbf{B}$ revealed numerous sharp and intense diffraction peaks which indicate good crystallinity (Figure 7). After grinding, intensity decrease and broadening of the peaks is observed that indicates partial alteration of the crystalline packing and possible amorphization.

FTIR spectra were recorded for the three compounds along with that of $\mathrm{PPh}_{4} \mathrm{I}$ for comparison. DFT calculations performed on $\left(\mathrm{PPh}_{4}\right)^{+}$and $\left[\mathrm{Cu}_{2} \mathrm{I}_{4}\right]^{2-}$ moieties (anharmonic computations, detailed in $\mathrm{SI}$ ), permit to simulate their IR signatures and to assign the vibration bands. Post-treatments were performed using the VMS package. ${ }^{73}$ Experimental FTIR spectra $\left(4000-500 \mathrm{~cm}^{-1}\right)$ are similar for all the compounds and clearly correspond to the tetraphenylphosphonium cation's signature. Simulated spectrum is in very good agreement with that of $\mathrm{PPh}_{4} \mathrm{I}$ (Figures S4-5). Main peaks observed at 1433, 1103, 722, 686 and $526 \mathrm{~cm}^{-1}$ can thus be attributed to combination of C-C and C-H vibrations. More specifically, the three highest wavenumbers comprise $\mathrm{C}-\mathrm{H}$ bending, rocking and wagging motions. The two lowest wavenumbers correspond to $\mathrm{C}-\mathrm{H}$ scissoring together with $\mathrm{C}-\mathrm{C}$ breathing. Furthermore, the anharmonic treatment demonstrates that all peaks between 1800 and $2800 \mathrm{~cm}^{-1}$ correspond to overtones and combination bands. Spectra have been also recorded in the far-IR region $\left(650-50 \mathrm{~cm}^{-1}\right)$ and present differences between the two polymorphs but with a common peak at $177 \mathrm{~cm}^{-1}$ (Figure S6). The spectra of $\mathbf{B} \boldsymbol{g}$ has different peaks compared with that of $\mathbf{B}\left(203,71 \mathrm{~cm}^{-1}\right)$ which are observed in $\mathbf{A}$ suggesting structural similarities between them. The peak at $177 \mathrm{~cm}^{-1}$ in $\mathbf{A}$ and $\mathbf{B}$ is found at $179 \mathrm{~cm}^{-1}$ in $\mathbf{B g}$. This peak, simulated at $168 \mathrm{~cm}^{-1}$, corresponds to $\mathrm{Cu}-\mathrm{I}$ bond stretching vibrations of $\left[\mathrm{Cu}_{2} \mathrm{I}_{4}\right]^{2-}$ (Figure S7). The experimental peak at $152 \mathrm{~cm}^{-1}$ can also be attributed to $\mathrm{Cu}-\mathrm{I}$ bond vibrations calculated at $127 \mathrm{~cm}^{-1}$. At lower frequencies, two peaks are observed which are different for the two polymorphs $\left(\mathbf{A}: 71,53 \mathrm{~cm}^{-1}\right.$ and $\mathbf{B}: 68$ and $\left.48 \mathrm{~cm}^{-1}\right)$. Corresponding values for $\mathbf{B} \boldsymbol{g}\left(71\right.$ and $\left.51 \mathrm{~cm}^{-1}\right)$ are closer to those of $\mathbf{A}$ indicating again structural similarities. From simulations, these two vibrations $\left(73\right.$ and $31 \mathrm{~cm}^{-1}$ ) may correspond to an out of plane bending and a wagging modes of the $\left[\mathrm{Cu}_{2} \mathrm{I}_{4}\right]^{2-}$ anion. Differences observed can be attributed to the different planar and folded geometries of the anion. Values reported for $(\mathrm{PNP})_{2}\left[\mathrm{Cu}_{2} \mathrm{I}_{4}\right]$ $\left(71 \text { and } 54 \mathrm{~cm}^{-1}\right)^{66}$ whose geometry is planar, are indeed close to those of $\mathbf{A}$.

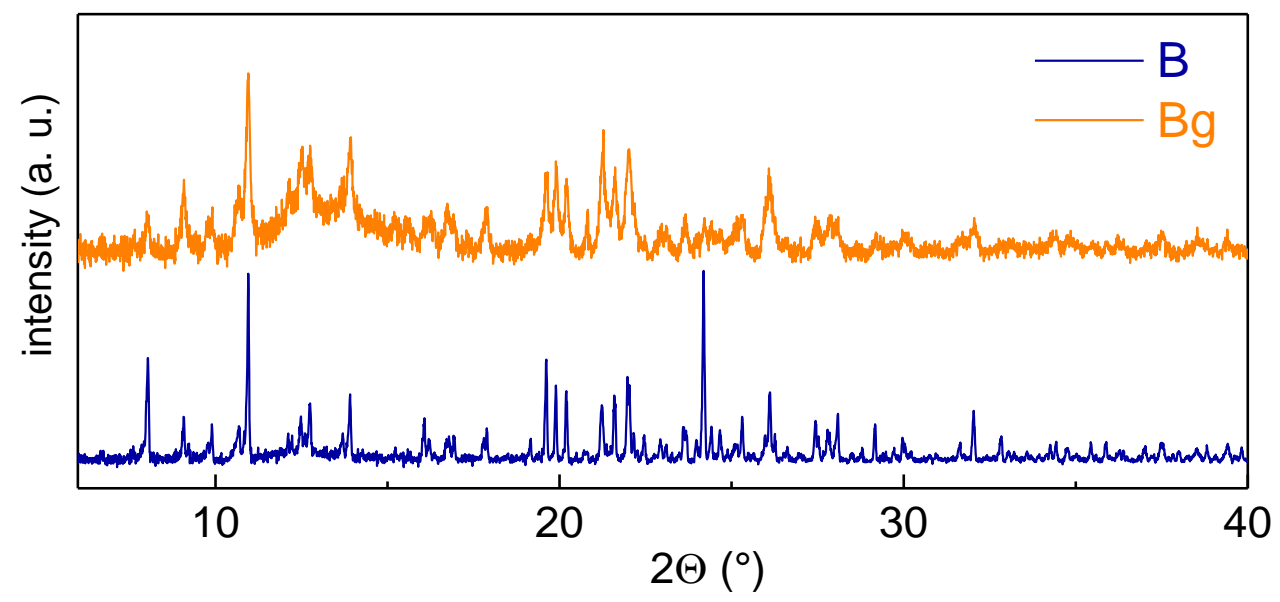

Figure 7. PXRD of $\mathbf{B}$ and $\mathbf{B} \boldsymbol{g}$ recorded at room temperature.

The reversibility of the mechanochromic effect was tested by solvent treatment but without success. With the different tested solvents, the initial blue emission of $\mathbf{B}$ is not recovered and instead either the yellow emission of $\mathbf{B} \boldsymbol{g}$ is maintained (cyclohexane, diethyl-ether) or a white emission appears 
(acetonitrile, acetone). This irreversibility can be explained by the formation of these copper iodide compounds which is highly dependent to the experimental conditions such as the solvent. This is illustrated by the rich polymorphism and isomerism displayed by this family of compounds.

To get insight into the local structure of the ground phase in light of that of the two polymorphs, solidstate NMR analysis has been conducted. In addition to the classical ${ }^{1} \mathrm{H}$ and ${ }^{13} \mathrm{C}$ nuclei, ${ }^{31} \mathrm{P}$ and ${ }^{63,65} \mathrm{Cu}$ ones have been studied. Those two latter are particularly relevant to probe the copper iodide structural geometries. ${ }^{74,75}{ }^{1} \mathrm{H}$ MAS NMR spectra (Figure S8) present broad signatures centered at 7.5 ppm which are in agreement with the phosphonium cation $\left(\mathrm{P}\left(\mathrm{C}_{6} \mathrm{H}_{5}\right)_{4}{ }^{+}\right)$with phenyl groups characteristics. ${ }^{13} \mathrm{C}$ MAS NMR spectra present two broad features around 135 and $120 \mathrm{ppm}$, the latter corresponding to carbon atoms bonded to the phosphorus atom (Figure S8). No significant difference is observed between the samples. The ${ }^{31} \mathrm{P}$ signatures shown in Figure 8, are also in accordance with the phosphonium cation. The singlet observed at $22 \mathrm{ppm}$ for A results from the crystallographically independent $\left(\mathrm{PPh}_{4}\right)^{+}$and for $\mathbf{B}$ the two peaks at 21 and $23 \mathrm{ppm}$ correspond to the two inequivalent cations. The different structural conformation of the phosphonium within the structure of the two polymorphs are thus revealed thanks to the sensitivity of the ${ }^{31} \mathrm{P}$ nucleus. The two peaks are also present in the ${ }^{31} \mathrm{P}$ spectrum of $\mathbf{B} \boldsymbol{g}$ but with a broadened feature. This indicates the preservation of the structure of $\mathbf{B}$ upon grinding but with creation of some local structural disorder in accordance with the PXRD analysis.

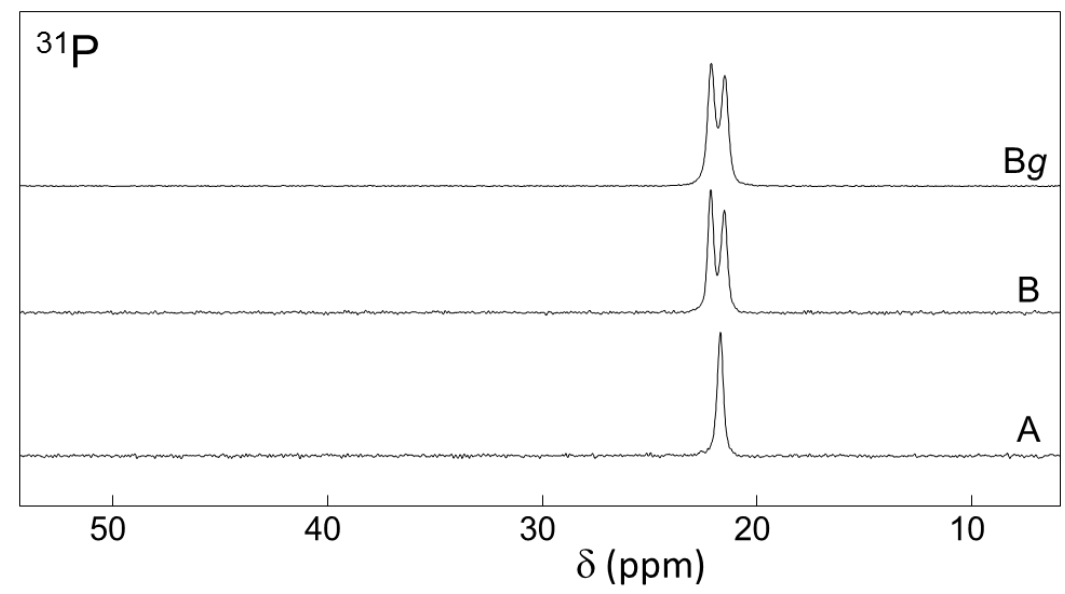

Figure 8. ${ }^{31} \mathrm{P}$ CPMAS solid state NMR spectra of $\left(\mathbf{P P h}_{4}\right)_{2}\left[\mathbf{C u}_{2} \mathbf{I}_{4}\right]-\mathbf{A}, \mathbf{B}$ and $\mathbf{B g}$.

The ${ }^{63} \mathrm{Cu}$ static NMR spectra are shown in Figure 9. They present particularly broad signals extending over 1.5 MHz. For $\mathbf{A}$, the quadrupolar coupling constant $\left(\mathrm{C}_{\mathrm{Q}}\right)$ is about $45.6 \mathrm{MHz}$, with asymmetry parameter $\left(\eta_{\mathrm{Q}}\right)$ of 0.34 . This large $\mathrm{C}_{\mathrm{Q}}$ value is typical of copper atoms in three-coordinated $\mathrm{CuI}_{3}$ geometry and is clearly distinct from the four-coordinate $\mathrm{PCuI}_{3}, \mathrm{P}_{2} \mathrm{CuI}_{2}$ and $\mathrm{CuI}_{4}$ copper environment signatures (usually $20-25 \mathrm{MHz} \mathrm{C}_{\mathrm{Q}}$ values). ${ }^{76}$ The ${ }^{63} \mathrm{Cu}$ NMR spectrum of $\mathbf{A}$ can be simulated using a single component (Figure S9), in agreement with the single $\mathrm{Cu}$ site in the crystal structure. In $\mathbf{B}$, the two individual components are still strongly overlapped (a deconvolution is suggested in Figure S10), despite the use of high magnetic field (17.6 T). Both $\mathrm{C}_{\mathrm{Q}}$ values are in the $45-47 \mathrm{MHz}$ range, again, in agreement with copper atoms in three-coordinated $\mathrm{CuI}_{3}$ geometry. The two polymorphs present distinct ${ }^{65} \mathrm{Cu} \mathrm{NMR}$ signatures but the correlation with their structure is difficult to establish at this stage. The spectra of $\mathbf{B g}$ is very similar to that of $\mathbf{B}$, indicating the preservation of the $\left[\mathrm{Cu}_{2} \mathrm{I}_{4}\right]^{2-}$ anion upon grinding. Partial 
amorphization is however not obvious in this case, probably due to predominance of the signal of intact crystalline part.

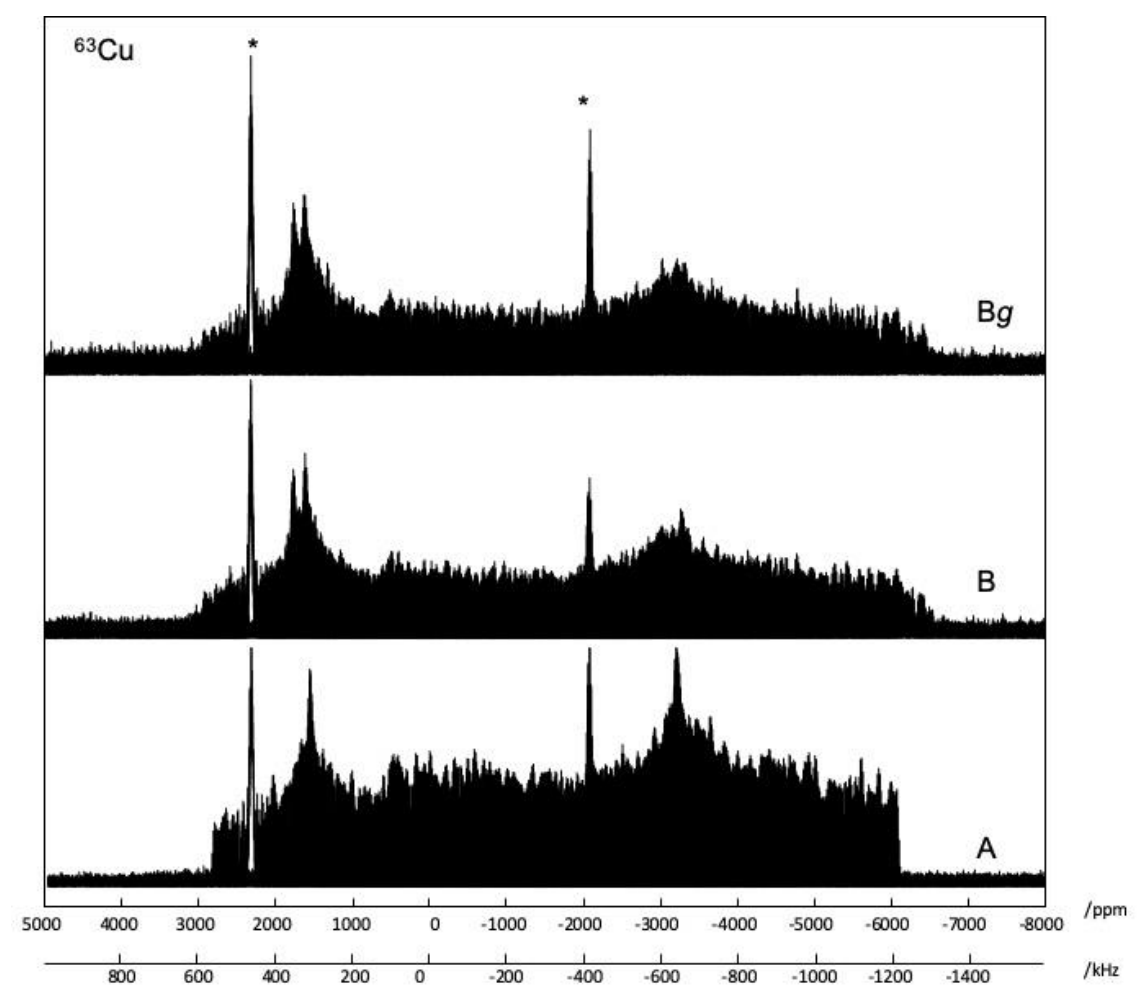

Figure 9. ${ }^{63} \mathrm{Cu}$ static WURST-QCPMG NMR spectra of $\left(\mathbf{P P h}_{4}\right)_{2}\left[\mathbf{C u}_{2} \mathbf{I} 4\right]-\mathbf{A}, \mathbf{B}$ and $\mathbf{B g}$. The span of the patterns is about $9000 \mathrm{ppm}$, corresponding to ca $1.7 \mathrm{MHz}$. The stars indicate signals due to the copper coil of the NMR probehead.

As shown in Figure 10, all studied compounds are slightly yellowish crystalline powders under daily light at room temperature whereas under UV illumination they present distinct luminescence colors with bright yellow, blue and yellowish emissions for $\mathbf{A}, \mathbf{B}$ and $\mathbf{B g}$, respectively. By lowering the temperature down to $77 \mathrm{~K}$, significant change of the emissions colors is observed with a yellow to orange shift for $\mathbf{A}$, a yellow to blue shift for $\mathbf{B} \boldsymbol{g}$ while for $\mathbf{B}$ the pristine blue emission turns into deeper blue. This phenomenon is reversible upon warming up with recovery of the initial emissions. $\mathbf{A}$ and $\mathbf{B g}$ thus present contrasted luminescence thermochromism. Because the temperature dependent emission color change is lesser for $\mathbf{B}$ compared with that of $\mathbf{B} \boldsymbol{g}$, the grinding process induces in some way luminescence thermochromism to the compound. 


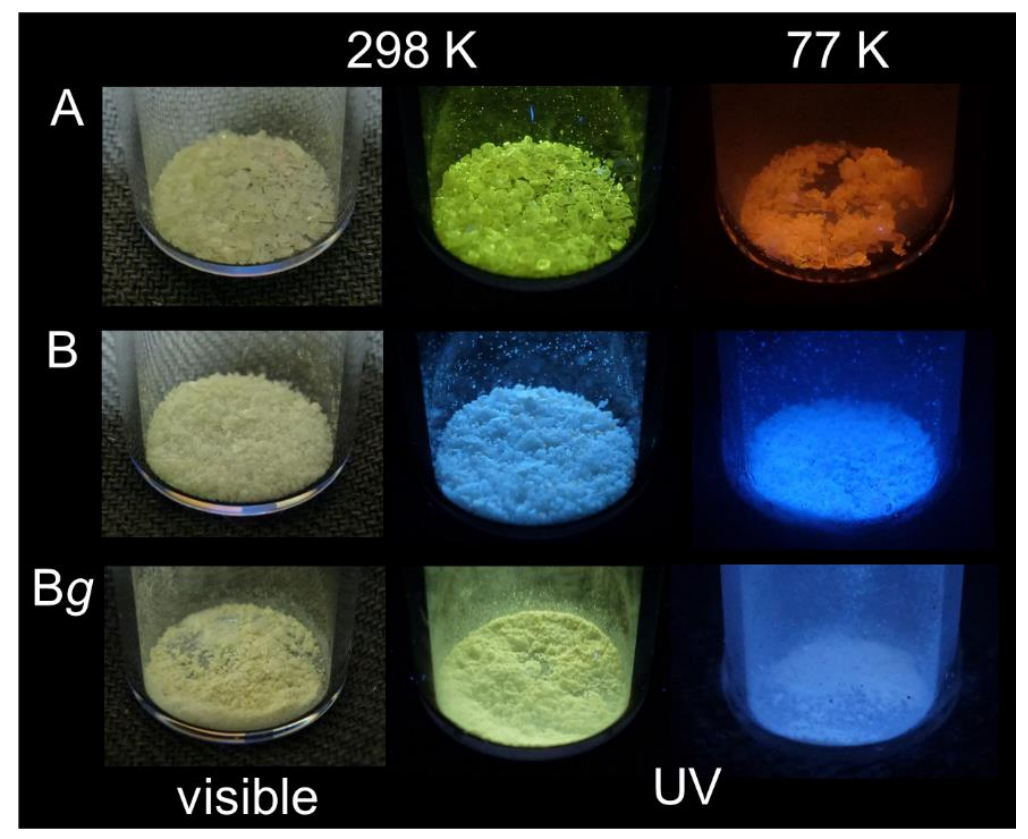

Figure 10. Photos of crystalline powder of $\left(\mathbf{P P h}_{4}\right)_{2}\left[\mathbf{C u}_{2} \mathbf{I}_{4}\right]-\mathbf{A}, \mathbf{B}$ and $\mathbf{B g}$ under visible light and UV irradiation (365 nm UV lamp) at room temperature $(298 \mathrm{~K})$ and in liquid nitrogen $(77 \mathrm{~K})$.

Solid-state emission and excitation spectra were recorded from 77 to 293 K. Corresponding temperaturedependent spectra are shown in Figure S12 and related data are reported in Table 2. As shown in Figure 11 , at $293 \mathrm{~K}$ the emission spectra of $\mathbf{A}$ displays an unstructured emission band centered at $545 \mathrm{~nm}\left(\lambda_{\mathrm{ex}}\right.$ $=380 \mathrm{~nm}$ ), in accordance with the observed yellow emission. The emission band of $\mathbf{B}$ centered at 465 $\mathrm{nm}$ presents a shoulder at $545 \mathrm{~nm}$ whereas for $\mathbf{B} \boldsymbol{g}$ this is the opposite, with the main emission band at $545 \mathrm{~nm}$ and the shoulder at $465 \mathrm{~nm}\left(\lambda_{\mathrm{ex}}=380 \mathrm{~nm}\right)$. The grinding thus induces a significant red-shit of the main emission of $80 \mathrm{~nm}$ that is among the largest values reported for mechanochromic compounds. ${ }^{77}$ This agrees with the contrasted color emission change from blue to yellow observed upon grinding (Figure 6). Because the emission spectra of $\mathbf{B} \boldsymbol{g}$ is clearly a combination of the emission of the $\mathbf{A}$ and $\mathbf{B}$ polymorphs, the mechanical solicitation seems to induce a transition between the two polymorphs.

The associated emission lifetimes present single exponential decays for $\mathbf{A}$ and $\mathbf{B}$ with $\tau=1.01$ and 0.07 $\mu$ s respectively, whereas $\mathbf{B} \boldsymbol{g}$ displays a biexponential decay with $\tau_{1}=0.14$ and $\tau_{2}=0.93 \mu$ s values (Figure S13). These measurements reveal the formation upon grinding of new emissive species with longer lifetime values, close to that of $\mathbf{A}$. This confirms the mechanical transformation of the $\mathbf{B}$ polymorph into the $\mathbf{A}$ one. The absolute internal quantum yields determined at room temperature are QY $=10,2$ and 1 $\%$ for $\mathbf{A}, \mathbf{B}$ and $\mathbf{B} \boldsymbol{g}$, respectively (Table 2). 

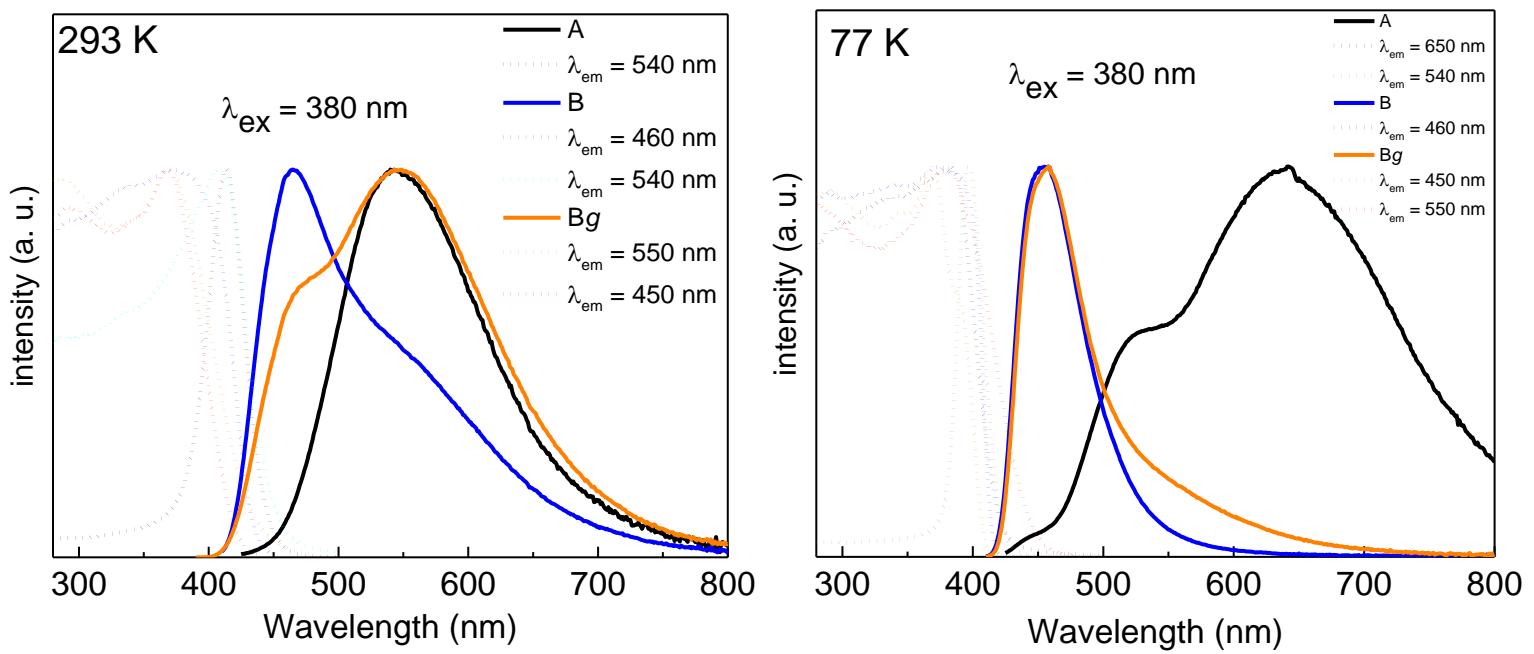

Figure 11. Solid-state luminescence spectra of A, B and $\mathbf{B g}$ at 293 and $77 \mathrm{~K}$ with normalized emission in solid lines and excitation spectra in dotted lines.

The emission band of $\mathbf{A}$ does not present large change upon lowering the temperature down to $175 \mathrm{~K}$ with a moderate intensity increase $\left(\lambda_{\mathrm{ex}}=380 \mathrm{~nm}\right)$. Below $175 \mathrm{~K}$, a new band centered at $650 \mathrm{~nm}$ appears whose intensity increases down to $77 \mathrm{~K}$, thus becoming eventually predominant compared with the 545 $\mathrm{nm}$ band (Figure 11 and S12). This agrees with the orange emission displayed at $77 \mathrm{~K}$ (Figure 10). Relatively narrow excitation bands are observed around $400 \mathrm{~nm}$ for the higher energy band $\left(\lambda_{\mathrm{em}}=540\right.$ $\mathrm{nm})$ at 293 and $77 \mathrm{~K}$ compared to the broad feature of the low energy one $\left(\lambda_{\mathrm{em}}=650 \mathrm{~nm}\right)$. For $\mathbf{B}$, the emission at $465 \mathrm{~nm}$ presents a moderate blue-shift (from 465 to $455 \mathrm{~nm}$ ) by lowering the temperature down to $77 \mathrm{~K}$ but with a great intensity increase $(\times 50)$. In opposite, the intensity of the secondary band at $545 \mathrm{~nm}$ decreases rapidly upon cooling and is not observed anymore at $77 \mathrm{~K}$ (Figure 11). No significant change is observed for the broad excitation bands $\left(\lambda_{\mathrm{em}}=460 \mathrm{~nm}\right)$. Bg presents similar temperature-dependent behavior compared with $\mathbf{B}$ by displaying a great increase of the intensity of the $460 \mathrm{~nm}$ emission band upon cooling. However, intensity of the emission band at $545 \mathrm{~nm}$ progressively increases from 293 to $200 \mathrm{~K}$. At $225 \mathrm{~K}$, the two emission bands have similar intensity and at $77 \mathrm{~K}$ the high energy one is largely predominant (Figure 11 and S12). The excitation bands present more structured profiles at low temperature $\left(\lambda_{\mathrm{em}}=450 \mathrm{~nm}\right)$. 

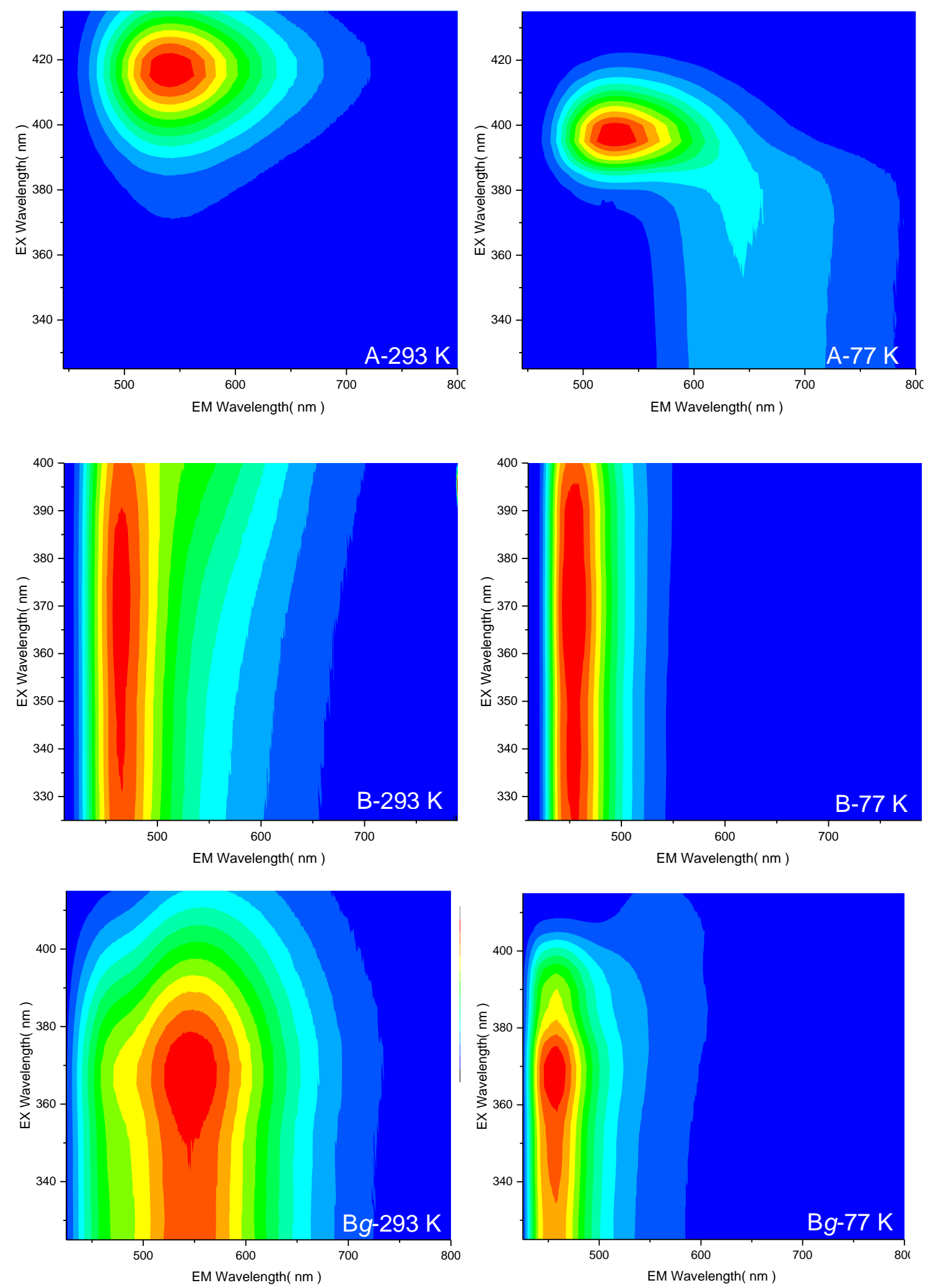

Figure 12. Solid-state photoluminescence maps (excitation $v s$. emission) of $\mathbf{A}, \mathbf{B}$ and $\mathbf{B} \boldsymbol{g}$ at 293 and $77 \mathrm{~K}$.

In addition to temperature-dependent emission properties, the three compounds also display excitationdependent emissions with important color tuning possibility. This is illustrated by the photoluminescence maps recorded at 293 and $77 \mathrm{~K}$ and reported in Figure 12. With a narrow excitation 
range around $415 \mathrm{~nm}$, the emission properties of polymorph $\mathbf{A}$ are not excitation-dependent at $293 \mathrm{~K}$ (temperature dependent luminescence spectra at $\lambda_{\mathrm{ex}}=415 \mathrm{~nm}$ are reported in Figure S12). In contrast, at $77 \mathrm{~K}$, the additional emission band at $650 \mathrm{~nm}$ is excitable at wavelength below $390 \mathrm{~nm}$. At $77 \mathrm{~K}$, the two emission bands ( 545 and $650 \mathrm{~nm})$ can thus be either simultaneously $\left(\lambda_{\mathrm{ex}}=385 \mathrm{~nm}\right)$ or independently excited ( $\lambda_{\mathrm{ex}}=415$ and $350 \mathrm{~nm}$ respectively, Figure S12). In the case of $\mathbf{B}$, there is no excitation dependent properties at $77 \mathrm{~K}$ with a wide range of possible excitations $(280-400 \mathrm{~nm}$ ) for the $465 \mathrm{~nm}$ emission band. This is different at $293 \mathrm{~K}$ with the second emission band at $550 \mathrm{~nm}$ that is excitable for wavelengths above $390 \mathrm{~nm}$ (Figure 12). This band cannot be solely excited but is, at $\lambda_{\mathrm{ex}}=415 \mathrm{~nm}$, of comparable intensity compared with the blue one (Figure S12). For Bg at $293 \mathrm{~K}$, the two emission bands at 560 and $465 \mathrm{~nm}$ can be both excited around $380 \mathrm{~nm}$. However, at $\lambda_{\mathrm{ex}}=415 \mathrm{~nm}$, the emission band at 560 can be solely excited (Figure S12). This dual emissions system is also present at $77 \mathrm{~K}$ but with a more contrasted excitation dependency. Indeed, the more intense emission band is this time the blue one (460 $\mathrm{nm})$ accompanied with the yellow one $(560 \mathrm{~nm})$. The latter can be excited individually at wavelengths above $\lambda_{\mathrm{ex}}=410 \mathrm{~nm}$ leading to a contrasted emission color change.

Table 2. Photoluminescence data of $\left(\mathbf{P P h}_{4}\right)_{2}\left[\mathbf{C u}_{2} \mathbf{I}_{4}\right]-\mathbf{A}, \mathbf{B}$ and $\mathbf{B g}$. Lifetimes and quantum yields have been measured at $293 \mathrm{~K}$.

\begin{tabular}{|c|c|c|c|c|}
\hline & \multicolumn{2}{|c|}{$\lambda_{\max }(\mathrm{nm})\left[\lambda_{\text {ex }}(\mathrm{nm})\right]$} & \multirow{2}{*}{$\begin{array}{c}\text { Lifetime } \tau(\mu \mathrm{s}) \\
{\left[\lambda_{\mathrm{em}}(\mathrm{nm})\right]}\end{array}$} & \multirow{2}{*}{$\begin{array}{c}\text { Quantum Yield QY (\%) } \\
{\left[\lambda_{\text {ex }}(\mathrm{nm})\right]}\end{array}$} \\
\hline & $293 \mathrm{~K}$ & $77 \mathrm{~K}$ & & \\
\hline \multirow{2}{*}{$\mathbf{A}$} & 545 [380] & $650[380]$ & \multirow{2}{*}{$1.01[550]$} & \multirow{2}{*}{$10[415]$} \\
\hline & 545 [415] & 533 [415] & & \\
\hline B & 465 [380] & 455 [380] & 0.07 [460] & $2[380]$ \\
\hline Bg & 545 [380] & 455 [380] & $\begin{array}{c}0.14(41 \%) 0.93(59 \%) \\
{[560]}\end{array}$ & $1[380]$ \\
\hline
\end{tabular}

Three different emission bands are thus observed for $\left(\mathrm{PPh}_{4}\right)_{2}\left[\mathrm{Cu}_{2} \mathrm{I}_{4}\right]$ (whatever the polymorph and the temperature) at roughly $\lambda_{\max }=460,550$, and $650 \mathrm{~nm}$. These transitions can originate from the two different emissive centers which are the organic cation $\left(\mathrm{PPh}_{4}\right)^{+}$and the inorganic anion $\left[\mathrm{Cu}_{2} \mathrm{I}_{4}\right]^{2-}$. Luminescence of tetraphenylphosphonium halides have been indeed reported and in particular $\mathrm{PPh}_{4} \mathrm{I}$ exhibits an emission at $\lambda_{\max }=430 \mathrm{~nm}$ which has been attributed to phosphorescence. ${ }^{78}$ On the anionic side, the emission properties of ionic copper halide compounds (no ligand in this case) can be attributed to ${ }^{3} \mathrm{XMCT}$ (X stands for halide) and ${ }^{3} \mathrm{MC}$ (metal centered) transitions with for the latter, possible influence of $\mathrm{Cu}-\mathrm{Cu}$ interactions. Only few photophysical characterizations have been reported in the literature for $\left[\mathrm{Cu}_{2} \mathrm{I}_{4}\right]^{2-}$ based compounds. For (btx) $\left[\mathrm{Cu}_{2} \mathrm{I}_{4}\right]$ (btx = 1,6bis(triethylmethylammonium)xylol), an emission band was observed at $\lambda_{\max }=463 \mathrm{~nm}$ which was surprisingly attributed to a MLCT transition. ${ }^{35}$ Single emission bands were also reported for $\left.[\mathrm{Ba} \text { (tetraglyme })_{2}\right]\left[\mathrm{Cu}_{2} \mathrm{I}_{4}\right]^{39}$ and $\left[\mathrm{Cu}(\mathrm{Me}-\mathrm{PPy} 3) \mathrm{I}_{2}\left[\mathrm{Cu}_{2} \mathrm{I}_{4}\right]^{63}\right.$ with $\lambda_{\max }=680$ and $660 \mathrm{~nm}$ respectively, and were assigned to mixed XMCT and MC transitions. In the cases of $\left(\mathrm{PPh}_{3} i \mathrm{Pr}\right)_{2}\left[\mathrm{Cu}_{2} \mathrm{I}_{4}\right]^{37}$ and $\{[\mathrm{K}($ benzo18-crown-6) $\left.]_{2}\left[\mathrm{Cu}_{2} \mathrm{I}_{4}\right]\right\}_{\mathrm{n}},{ }^{38}$ dual emissions were recorded at $\lambda_{\max }=447,558 \mathrm{~nm}$ and at $\lambda_{\max }=465,632$ $\mathrm{nm}$. These emissions were also attributed to XMCT and MC excited states, excepted the high energy band of $\left(\mathrm{PPh}_{3} i \mathrm{Pr}\right)_{2}\left[\mathrm{Cu}_{2} \mathrm{I}_{4}\right]^{37}$ that was assigned to a cation centered transition. From these previous studies, 
the assignment of the emission bands is not straightforward and were usually not supported by theoretical study. The only one theoretical approach was reported for $\left[\mathrm{Cu}(\mathrm{Me}-\mathrm{PPy} 3) \mathrm{I}_{2}\left[\mathrm{Cu}_{2} \mathrm{I}_{4}\right]^{63}\right.$ and despite large cation-anion distances, transitions from the MOs of the anion to those of the cation were suggested.

The diverse and nebulous emission origins, prompted us to perform DFT (Density Functional Theory) computations, in order to get a clear vision of the electronic structure of $\left(\mathrm{PPh}_{4}\right)_{2}\left[\mathrm{Cu}_{2} \mathrm{I}_{4}\right]$ and have an accurate assignment of the emission properties. These calculations were carried on with the Gaussian16 package ${ }^{79}$ using the PBE0 functional together with the LANL2DZ basis augmented with polarization functions for $\mathrm{H}, \mathrm{C}$ and $\mathrm{P}$ atoms, and the triple $\zeta$ basis set DEF2TZVP for $\mathrm{Cu}$ and $\mathrm{I}$ atoms (details in SI). ${ }^{80,81}$ The two potential emissive centers, $\left(\mathrm{PPh}_{4}\right)^{+}$and $\left[\mathrm{Cu}_{2} \mathrm{I}_{4}\right]^{2-}$, were treated independently because of the large intermolecular distances in the crystalline structures that precludes electronic transfer.

The $\left(\mathrm{PPh}_{4}\right)^{+}$moiety was computed without symmetry constrain but the relaxed structure can be approximated to the $S_{4}$ symmetry point group. The four P-C bond lengths have a mean value of 1.811 $\AA$ and the C-P-C angles lie between 108 and $110^{\circ}$, leading to a slightly distorted tetrahedron. These values are in agreement with the corresponding experimental ones of 1.795(5) $\AA$ and 109.50(2) ${ }^{\circ}$ (mean values). As shown in the orbital diagram in Figure 13, the last occupied orbitals are $\pi$-bonding ones and centered on phenyl moieties whereas the unoccupied ones are localized on the phosphorus atom together with phenyl moieties with a $\pi^{*}$-antibonding character. The optimized structure exhibits a gap of $c a 6$ $\mathrm{eV}$, it is therefore a very stable structure from thermodynamics viewpoint. The computed triplet excited state of $\left(\mathrm{PPh}_{4}\right)^{+}$keeps the pseudo $S_{4}$ symmetry point group. In that case the $\mathrm{P}$-C bonds are ranging from 1.792 to $1.813 \AA$ and angles from 107 to $110^{\circ}$. Therefore, the structural distortion appears to be stronger at the excited state than at the ground state. The corresponding simulated electronic phosphorescence is centered at $462 \mathrm{~nm}$. Vibrational contributions to electronic transitions were then taken into account to simulate the emission spectrum using the so-called Adiabatic Shift ansatz (vibrational modes detailed in SI). ${ }^{82,83}$ For this compound, temperature effects were also considered during the vibronic calculation. ${ }^{84}$ The simulated emission curve (Figure S14), is in a very good agreement with the emission spectra of $\mathrm{PPh}_{4} \mathrm{I}$ recorded at room temperature. These results demonstrate that $\mathrm{PPh}_{4}{ }^{+}$can be responsible for the emission at $460 \mathrm{~nm}$ observed for B. Furthermore, the simulated IR spectra and experimental FTIR spectra of $\mathrm{PPh}_{4} \mathrm{I}$ are in good agreement (Figure S5), giving confidence in this analysis. 

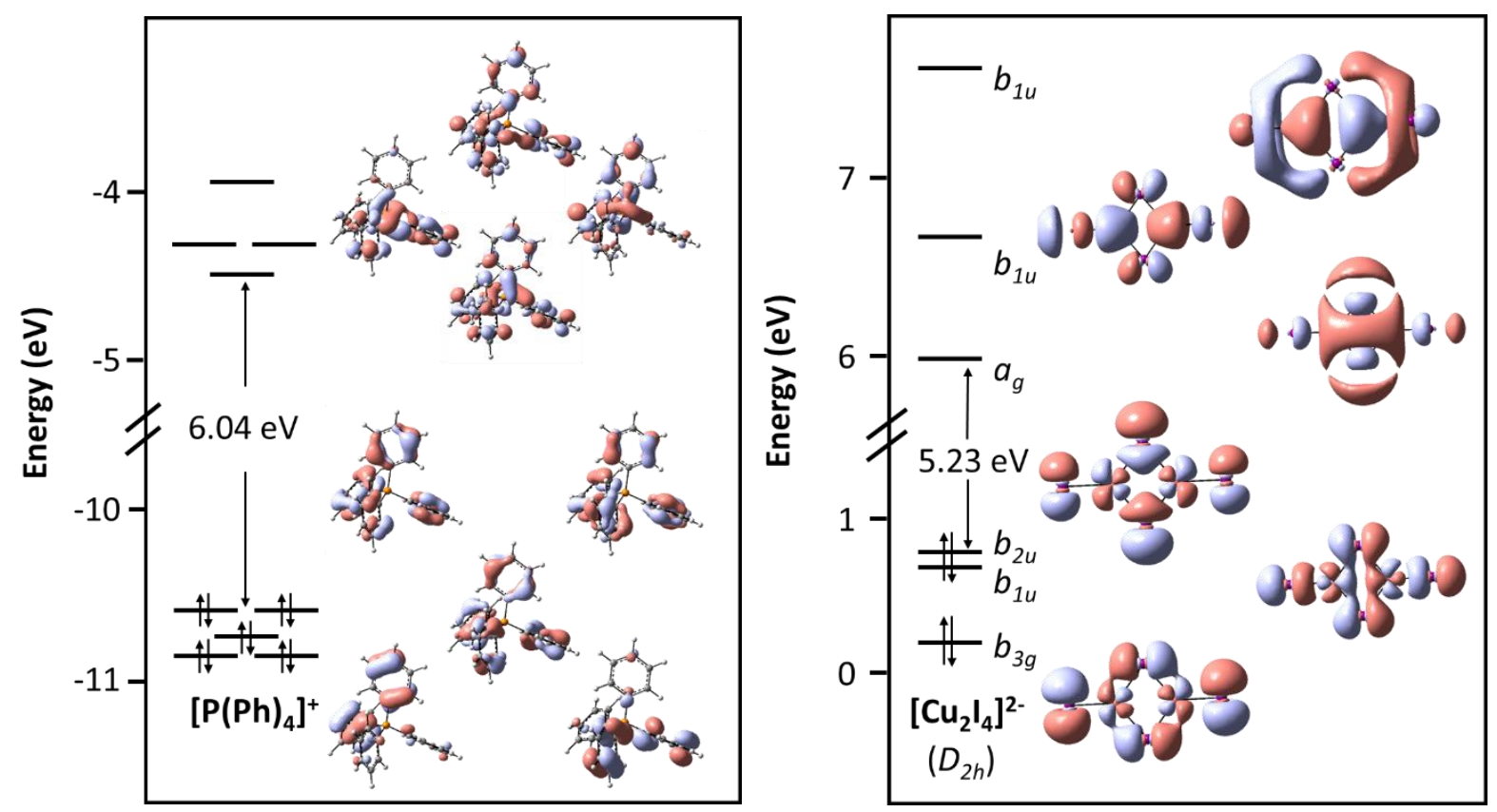

Figure 13. Kohn-Sham orbital diagrams of $\mathrm{PPh}_{4}{ }^{+}$and $\left[\mathrm{Cu}_{2} \mathrm{I}_{4}\right]^{2-}$ at their ground states.

For $\left[\mathrm{Cu}_{2} \mathrm{I}_{4}\right]^{2-}$, the two different geometries found in the polymorphs, planar and folded, were used as starting points to optimize the GS. It turned out that both structures converge to the same planar optimized geometry with the $D_{2 h}$ symmetry. This could indicate that the folded geometry results from constraints of the crystalline packing. In this planar relaxed geometry, the computed $\mathrm{Cu}-\mathrm{I} \mu_{1}$ and $\mathrm{Cu}-\mathrm{I} \mu_{2}$ bond distances values of 2.571 and $2.658 \AA$ respectively, are in agreement with the experimental data of 2.495(1) and 2.587(1) $\AA$ (polymorph A). This is similar for the angles with computed values of $\mathrm{I} \mu_{1}$ $\mathrm{Cu}-\mathrm{I} \mu_{2}=128.2^{\circ}$ and $\mathrm{I} \mu_{2}-\mathrm{Cu}-\mathrm{I} \mu_{2}=103.6^{\circ}$ and corresponding experimental ones of $124.68(3)^{\circ}$ and $110.34(3)^{\circ}$. Calculated $\mathrm{Cu}-\mathrm{Cu}$ bond distance of $3.288 \AA$ is in relative good accordance with the experimental one of 2.955(1) $\AA$. As shown in the orbital diagram in Figure 13, the HOMO and HOMO1,2 are mainly localized on iodide atoms with smaller contribution of $\mathrm{Cu}$ atoms (3d). These latters present a strong $\mathrm{Cu}-\mathrm{I} \mu_{2}$ bonding and $\mathrm{Cu}-\mathrm{I} \mu_{1}$ antibonding characters. The LUMO possesses a strong $\mathrm{Cu}-$ $\mathrm{Cu}$ bonding character which will lead to a strong shortening of the bond length at the excited state. The computed gap of $5.2 \mathrm{eV}$ is also large. The most intense absorption transitions calculated by TD-DFT mainly correspond to, HOMO $\rightarrow$ LUMO, HOMO-1 $\rightarrow$ LUMO transitions with wavelengths around $290 \mathrm{~nm}$. These calculated wavelengths are in reasonable agreement with the experimental broad absorption band centered at $325 \mathrm{~nm}$ (Figure S11). The absorption transitions have thus mixed ${ }^{1} \mathrm{XMCT}$ and ${ }^{1} \mathrm{MC}$ character. Two triplet excited states were calculated for $\left[\mathrm{Cu}_{2} \mathrm{I}_{4}\right]^{2-}$ and, as expected, their optimized geometries present a strong shortening of the $\mathrm{Cu}-\mathrm{Cu}$ distance $(2.463$ and $2.468 \AA$ ) relative to that of the fundamental state. In both cases, the $\mathrm{I} \mu_{2}$ atoms leave their positions and become bonded to a single copper atom, leading to two $\mathrm{CuI}_{2}$ entities linked by the short $\mathrm{Cu}-\mathrm{Cu}$ bond. The flexibility of copper iodides may account for this coordination change. The first excited state computed in TD-DFT, has for origin a transition from the HOMO-1 into the LUMO with $\mathrm{Cu}-\mathrm{Cu}$ bonding characteristic. Therefore, the corresponding transition is of ${ }^{3} \mathrm{XMCT}$ and ${ }^{3} \mathrm{MC}$ character. The calculated emission wavelength is around $620 \mathrm{~nm}$ which could represent the experimental emission centered at $550 \mathrm{~nm}$. In this excited state, the structure is indeed strongly distorted, both $\mathrm{I} \mu_{2}$ become $\mathrm{I} \mu_{1}$ and two sets of $\mathrm{Cu}-\mathrm{I}$ appear $(2 \times 2.649$ and 
$2 \times 2.602 \AA$ ) with I-Cu-I angle value of $108^{\circ}$. The second excited state was calculated using the unrestricted approach. In that case, the $C_{s}$ symmetry is found upon optimization. The corresponding mean $\mathrm{Cu}-\mathrm{I}$ distances are $2.598 \AA$ and the I-Cu-I angle is of $109^{\circ}$. It should be pointed out that both triplets have a similar geometrical shape, the $\mathrm{Cu}$-I being shorter and the structure less distorted for this second excited state comparatively to the first one. The spin density (Figure S15) clearly demonstrates that the unpaired electrons are shared by the $\mathrm{Cu}$ atoms. This excited state gives rise to an emission wavelength computed at $840 \mathrm{~nm}$ which is comparable to the experimental one at $650 \mathrm{~nm}$. Significant energetic deviations between the computed emissions and the experimental ones are here obtained $(0.25$ $\mathrm{eV}$ and $0.43 \mathrm{eV}$ ). The computed redshift between the two emissions around $0.52 \mathrm{eV}$ is however relatively close to the experimental one $(0.35 \mathrm{eV})$.

According to the DFT calculations, the different emission bands observed for $\left(\mathrm{PPh}_{4}\right)_{2}\left[\mathrm{Cu}_{2} \mathrm{I}_{4}\right]$ originate either from the $\left(\mathrm{PPh}_{4}\right)^{+}$organic cation $\left(\lambda_{\max }=460 \mathrm{~nm}\right)$ or from the $\left[\mathrm{Cu}_{2} \mathrm{I}_{4}\right]^{2-}$ anion $\left(\lambda_{\max }=550\right.$, and $650 \mathrm{~nm}$ ) (Figure S16). Activation of these two emissive centers appears to be dependent on the molecular arrangement in the solid-state. The lack of the blue band for polymorph $\mathbf{A}$ can be related to the $\pi$-orbital overlap present in its crystalline structure that are deleterious for the emission of phenylbased system. This effect can be referred to ACQ 'aggregation-caused quenching' phenomenon commonly encountered for $\pi$-conjugated motifs. ${ }^{85}$ The fact that the red band $\left(\lambda_{\max }=650 \mathrm{~nm}\right)$ is not observed for polymorph $\mathbf{B}$ can be attributed to the structural geometry of the $\left[\mathrm{Cu}_{2} \mathrm{I}_{4}\right]^{2-}$ anion. This low energy band is indeed theoretically predicted for the planar geometry but could be non-radiative for the folded form as in $\mathbf{B}$.

The difference between the two polymorphs is also evidenced by their temperature-dependent emission properties. Indeed, a contrasted luminescence thermochromism is observed for $\mathbf{A}$ whereas for polymorph $\mathbf{B}$ its temperature dependent emission is less pronounced. Luminescence thermochromism of $\mathbf{B}$ is however induced by mechanical solicitation, $\mathbf{B} \boldsymbol{g}$ displaying a yellow emission at room temperature that becomes blue upon decreasing the temperature. This blue shift contrasts with the observed redshift of $\mathbf{A}$ upon cooling. The thermochromism displayed by $\mathbf{A}$ can be related to that of $\left[\mathrm{Cu}_{4} \mathrm{I}_{4} \mathrm{~L}_{4}\right]$ cubane clusters with variation in temperature of the relative intensities of two emission bands corresponding to two different excited states (Figure S16). ${ }^{24,25}$ For $\mathbf{B g}$, the origin is different because the emission bands do not originate from the same molecule but come from two independent emissive centers namely $\left(\mathrm{PPh}_{4}\right)^{+}$and $\left[\mathrm{Cu}_{2} \mathrm{I}_{4}\right]^{2-}$.

The luminescence mechanochromism displayed by $\mathbf{B}$ appears to be the result of a polymorphic transition. The mechanical solicitation induces a partial transformation of the $\mathbf{B}$ polymorph into the $\mathbf{A}$ one. From DFT geometrical optimization, $\mathbf{A}$ is actually the most thermodynamically stable polymorph. Structural characterizations indicate that this created $\mathbf{A}$ polymorph is in a disordered (amorphous) phase in $\mathbf{B g}$. The mechanochromic mechanism can be thus related to modification of the structural packing and in particular of the $\pi-\pi$ interactions between the $\left(\mathrm{PPh}_{4}\right)^{+}$cations. Structural disorder may favors the formation of such intermolecular interactions that quench the emission band of $\left(\mathrm{PPh}_{4}\right)^{+}$and consequently enhance that of the low-energy exhibited by $\left[\mathrm{Cu}_{2} \mathrm{I}_{4}\right]^{2-}$. The present mechanochromism thus implies intermolecular mechanical transformation that contrasts to intramolecular mechanism reported for $\left[\mathrm{Cu}_{4} \mathrm{I}_{4} \mathrm{~L}_{4}\right]$ 
cubane clusters for which cuprophilic interactions are modified. ${ }^{26 f}$ By displaying mechanochromic properties in close relation with polymorphism, the flexible adaptation of copper iodide compounds to the structural environment is highlighted in the present study.

\section{Conclusion.}

The two studied copper iodide crystalline polymorphs displaying distinct luminescence properties constitute a neat example of molecular packing-dependent emission. Structural and photophysical characterizations of these real polymorphs permit to reveal their original stimuli-responsive properties. Theoretical investigations allowed to get insight into the mechanisms at play by rationalizing the emission properties and showing that the cationic and anionic counterparts are both emissive centers.

Combined luminescence thermochromism and mechanochromism are demonstrated for these ionic copper iodide compounds. Their emission properties are additionally highly dependent on the excitation wavelength. By displaying luminescence properties that dependent on crystalline structure, excitation wavelength, temperature and mechanical solicitation, these compounds offer a great possibility of color control and switch. By reporting original photoactive properties of ionic copper iodide compounds, this study demonstrates the potentialities of these family of compounds for developing optical stimuliresponsive materials.

Acknowledgments. CMC is grateful for financial support from the Institut Universitaire de France (IUF). Financial support from the IR-RMN-THC Fr3050 CNRS for conducting the research is gratefully acknowledged. H. Brault and R. Utrera-Melero are thanked for their assistance. CL thanks access to the HPC resources of TGCC under allocation 2019-A0070911052.

\section{ASSOCIATED CONTENT}

Supporting Information Available. The X-ray crystallographic files (CIF), the experimental section, the DFT and other characterization data. This information is available free of charge via the Internet at http://pubs.acs.org.

\section{References}

(1) Naren, G.; Hsu, C.-W.; Li, S.; Morimoto, M.; Tang, S.; Hernando, J.; Guirado, G.; Irie, M.; Raymo, F. M.; Sundén, H.; Andréasson, J.; An all-photonic full color RGB system based on molecular photoswitches. Nature Com. 2019, 3996-4003.

(2) Huang, G.; Xia, Q.; Huang, W.; Tian, J.; He, Z.; Li, B. S.; Tang, B. Z. Multiple Anti-Counterfeiting Guarantees from a Simple Tetraphenylethylene Derivative - High-Contrasted and Multi-State Mechanochromism and Photochromism. Angew. Chem. Int. Ed. 2019, 58, 17814-17819.

(3) Wenger, O. S. Photoactive Complexes with Earth-Abundant Metals. J. Am. Chem. Soc. 2018, 140, 1352213533 .

(4) Hamze, R.; Peltier, J. L.; Sylvinson, D.; Jung, M.; Cardenas, J.; Haiges, R.; Soleilhavoup, M.; Jazzar, R.; Djurovich, P. I.; Bertrand, G.; Thompson, M. E. Eliminating nonradiative decay in $\mathrm{Cu}(\mathrm{I})$ emitters: >99\% quantum efficiency and microsecond lifetime. Science 2019, 363, 601-606. 
(5) Yam, V. W.-W.; Au, V. K.-M.; Leung, S. Y.-L. Light-Emitting Self-Assembled Materials based on $\mathrm{d}^{8}$ and $\mathrm{d}^{10}$ Transition Metal Complexes. Chem. Rev. 2015, 115, 7589-7728.

(6) Cariati, E.; Lucenti, E.; Botta, C.; Giovanella, U.; Marinotto, D.;Righetto, S. Cu(I) hybrid inorganic-organic materials with intriguing stimuli responsive and optoelectronic properties. Coord. Chem. Rev. 2016, 306, 566-614.

(7) $\mathrm{Hu}, \mathrm{Z}$; Deibert, B. J.; Li, J. Luminescent metal-organic frameworks for chemical sensing and explosive detection. Chem. Soc. Rev. 201443 5815-5840.

(8) Wenger, O. S. Vapochromism in Organometallic and Coordination Complexes: Chemical Sensors for Volatile Organic Compounds. Chem. Rev. 2013, 113, 3686-3733.

(9) Peng, R.; Li, M.; Li, D. Copper(I) halides: A versatile family in coordination chemistry and crystal engineering. Coord. Chem. Rev. 2010, 254, 1-18.

(10) Kobayashi, A.; Kato M. Stimuli-responsive Luminescent Copper(I) Complexes for Intelligent Emissive Devices. Chem. Lett. 2017, 46, 154-162.

(11) Wallesch, M.; Volz, D.; Zink, D. M.; Schepers, U.; Nieger, M.; Baumann, T.; Brase, S. Bright coppertunities: Multinuclear CuI complexes with N-P ligands and their applications. Chem. Eur. J, 2014, 20, 6578-6590.

(12) Fang, Y.; Liu, W.; Teat, S. J.; Dey, G.; Shen, Z.; An, L.; Yu, D.; Wang, L.; O’Carroll, D. M.; Li, J. A Systematic Approach to Achieving High Performance Hybrid Lighting Phosphors with Excellent Thermal- and Photostability. Adv. Funct. Mater. 2017, 27, 1603444.

(13) Yu, T.-L.; Guo, Y.-M.; Wu, G.-X.; Yang, X.-F.; Xue, M.; Fu, Y.-L.; Wang, M.-S. Recent progress of d ${ }^{10}$ iodoargentate(I)/iodocuprate(I) hybrids: Structural diversity, directed synthesis, and photochromic/thermochromic properties. Coord. Chem. Rev. 397, 2019, 91-111.

(14) Yu, Y.; Zhang, X.-M.; Ma, J.-P.; Liu, Q.-K.; Wang, P.; Dong, Y.-B. Cu(I)-MOF: naked-eye colorimetric sensor for humidity and formaldehyde in single-crystal-to-single-crystal fashion. Chem. Commun., 2014, 50, 14441446.

(15) Wang, J.-H.; Li, M.; Li, D. A dynamic, luminescent and entangled MOF as a qualitative sensor for volatile organic solvents and a quantitative monitor for acetonitrile vapour. Chem. Sci. 2013, 4, 1793-1801.

(16) Conesa-Egea, J.; Gallardo-Martínez, J.; Delgado, S.; Martínez, J. I.; Gonzalez-Platas, J.; Fernández-Moreira, V.; Rodríguez-Mendoza, U. R.; Ocón, P.; Zamora, F.; Amo-Ochoa, P.; Multistimuli Response Micro- and Nanolayers of a Coordination Polymer Based on $\mathrm{Cu}_{2} \mathrm{I}_{2}$ Chains Linked by 2-Aminopyrazine. Small 2017, 13, 1700965 .

(17) Kitagawa, H.; Ohtsu, H.; Kawano, M. Kinetic Assembly of a Thermally Stable Porous Coordination Network Based on Labile CuI Units and the Visualization of $\mathrm{I}_{2}$ Sorption. Angew. Chem. Int. Ed. 2013, 52, 12395-12399.

(18) Shi, D.; Zheng, R.; Sun, M.-J.; Cao, X.; Sun, C.-X.; Cui, C.-J.; Liu, C.-S.; Zhao, J.; Du. M. Semiconductive Copper(I)-Organic Frameworks for Efficient Light-Driven Hydrogen Generation Without Additional Photosensitizers and Cocatalysts. Angew. Chem. Int. Ed. 2017, 56, 14637-14641.

(19) Zink, D. M.; Volz, D.; Baumann, T.; Mydlak, M.; Flügge, H.; Friedrichs, J.; Nieger, M.; Bräse, S. Heteroleptic, Dinuclear Copper(I) Complexes for Application in Organic Light-Emitting Diodes. Chem. Mater. 2013, 25, 4471-4486.

(20) Liu, Z.; Qiu, J.; Wei, F.; Wang, J.; Liu, X.; Helander, M.G.; Rodney, S.; Wang, Z.; Bian, Z.; Lu, Z.; Thompson, M. E.; Huang, C. Simple and High Efficiency Phosphorescence Organic Light-Emitting Diodes with Codeposited Copper(I) Emitter. Chem. Mater. 2014 26, 2368-2373.

(21) You, Z.; Li, H.; Zhang, L.; Yu, B.; Zhang,J.; Wu, X. A Host Material for Deep-Blue Electrophosphorescence Based on a Cuprous Metal-Organic Framework. J. Phys. Chem. C 2017, 121, 23072-23079.

(22) Liu, W.; Fang, Y. ; Li. J. Copper Iodide Based Hybrid Phosphors for Energy-Efficient General Lighting Technologies. Adv. Funct. Mater. 2018, 28, 1705593.

(23) Xie, M.; Han, C.; Zhang, J.; Xie, G.; Xu, H. White Electroluminescent Phosphine-Chelated Copper Iodide Nanoclusters. Chem. Mater. 2017, 29, 6606-6610.

(24) (a) Ford, P. C.; Cariati, E.; Bourasssa, J. Photoluminescence Properties of Multinuclear Copper(I) Compounds. Chem. Rev. 1999, 99, 3625-3647. (b) Kim, T. H.; Shin, Y. W.; Jung, J. H.; Kim, J. S.; Kim, J. Crystalto-crystal transformation between three $\mathrm{CuI}$ coordination polymers and structural evidence for luminescence thermochromism. Angew. Chem., Int. Ed. 2008, 47, 685-688. (c) Lapprand, A.; Dutartre, M.; Khiri, N.; Levert, E.; Fortin, D.; Rousselin, Y.; Soldera, A.; Jugé, S.; Harvey, P. D. Luminescent P-chirogenic copper clusters. Inorg. Chem. 2013, 52, 7958-7967. (d) Fu, Z.: Lin, J.; Wang, L.; Li, C.; Yan, W.; Wu, T. Cuprous Iodide Pseudopolymorphs Based on Imidazole Ligand and Their Luminescence Thermochromism. Cryst. Growth Des. 
2016, 16, 2322-2327. (e) Zhan, S.-Z.; Li, M.; Zhou, X.P.; Wang, J.-H.; Yang J.-R.; Li, D. When $\mathrm{Cu}_{4} \mathrm{I}_{4}$ cubane meets $\mathrm{Cu}_{3}$ (pyrazolate) $)_{3}$ triangle: dynamic interplay between two classical luminophores functioning in a reversibly thermochromic coordination polymer. Chem. Commun., 2011, 47, 12441-12443. (f) Zhan, S.-Z.; Li, M.; Ng, S. W.; Li, D. Luminescent Metal-Organic Frameworks (MOFs) as a Chemopalette: Tuning the Thermochromic Behavior of Dual-Emissive Phosphorescence by Adjusting the Supramolecular Microenvironments. Chem. Eur. J. 2013, 19, 10217-10225.

(25) Perruchas, S.; Tard, C.; Le Goff, X. F., Fargues, A.; Garcia, A.; Kahlal, S.; Saillard, J.-Y.; Gacoin, T.; Boilot, J.-P. Thermochromic Luminescence of Copper Iodide Clusters: The Case of Phosphine Ligands. Inorg. Chem. 2011, 50, 10682-10692.

(26) (a) Perruchas, S.; Le Goff, X. F.; Maron, S.; Maurin, I.; Guillen, F.; Garcia, A.; Gacoin, T.; Boilot, J.-P. Mechanochromic and Thermochromic Luminescence of a Copper Iodide Cluster. J. Am. Chem. Soc. 2010, 132, 10967-10969. (b) Shan, X.-C.; Jiang, F.-L.; Zhang, H.-B.; Qian, X.-Y.; Chen, L.; Wu, M.-Y.; Al-Thabaiti, S. A.; Hong, M.-C. A solid AND logic stimuli-responsive material with bright nondestructive performance designed by sensitive cuprophilicity. Chem. Commun. 2013, 49, 10227-10229. (c) Shan, X.-C.; Jiang, F.-L.; Chen, L.; Wu, M.Y.; Pan, J.; Wan, X.-Y.; Hong, M.-C. Using cuprophilicity as a multi-responsive chromophore switching color in response to temperature, mechanical force and solvent vapors. J. Mater. Chem. C, 2013, 4339-4349. (d) Benito, Q.; Le Goff, X. F.; Maron, S.; Fargues, A.; Garcia, A.; Martineau, C.; Taulelle, F.; Kahlal, S.; Gacoin, T.; Boilot, J.-P.; Perruchas, S. Polymorphic Copper Iodide Clusters: Insights into the Mechanochromic Luminescence Properties. J. Am. Chem. Soc., 2014, 136, 11311-11320. (e) Huitorel, B. ; El Moll, H. ; Cordier, M. ; Fargues, A. ; Garcia, A. ; Massuyeau, F. ; Martineau-Corcos, C. ; Gacoin, T. ; Perruchas, S. ; Luminescence Mechanochromism induced by Cluster Isomerization. Inorg. Chem. 2017, 56, 12379-12388. (f) Huitorel, B.; Utrera-Melero, R.; Massuyeau, F. ; Mevelec, J.-Y.; Baptiste, B. ; Polian, A.; Gacoin, T. ; Martineau-Corcos, C. ; Perruchas, S. Luminescence mechanochromism of copper iodide clusters: a rational investigation. Dalton Trans. 2019, 48, 78997909.

(27) (a) Kobayashi, A.; Yoshida, Y.; Yoshida, M.; Kato, M. Mechanochromic Switching between Delayed Fluorescence and Phosphorescence of Luminescent Coordination Polymers Composed of Dinuclear Copper(I) Iodide Rhombic Cores. Chem. Eur. J. 2018, 24, 14750-14759. (b) Wen, T.; Zhang, D.-X.; Zhang, H.-X.; Zhang, H.-B.; Zhang, J.; Li, D.-S. Redox-active Cu(I) boron imidazolate framework for mechanochromic and catalytic applications. Chem. Commun. 2014, 50, 8754-8756. (c) Xiao, Q.; Zheng, J.; Li, M.; Zhan, S.-Z.; Wang, J.-H.; Li, D., Mechanically Triggered Fluorescence/Phosphorescence Switching in the Excimers of Planar Trinuclear Copper(I) Pyrazolate Complexes. Inorg. Chem. 2014, 53, 11604-11615. (d) Deshmukh, M. S.; Yadav, A.; Pant, R.; Boomishankar, R. Thermochromic and Mechanochromic Luminescence Umpolung in Isostructural Metal-Organic Frameworks Based on $\mathrm{Cu}_{6} \mathrm{I}_{6}$ Clusters. Inorg. Chem. 2015, 54, 1337-1345. (e) Chen, K.; Nenzel, M. M.; Brown, T. M.; Catalano, V. J. Subtle Modulation of $\mathrm{Cu}_{4} \mathrm{X}_{4} \mathrm{~L}_{2}$ Phosphine Cluster Cores Leads to Changes in Luminescence. Inorg. Chem. 2015, 54, 6900-6909. (f) Kwon, E.; Kim, J.; Lee, K. Y.; Kim, T. H. Non-PhaseTransition Luminescence Mechanochromism of a Copper(I) Coordination Polymer Inorg. Chem. 2017, 56, 943949. (g) Hu, L.-X.; Gao, M.; Wen, T.; Kang, Y.; Chen, S. Synthesis of Halide-Modulated Cuprous(I) Coordination Polymers with Mechanochromic and Photocatalytic Properties. Inorg. Chem. 2017, 56, 6507-6511. (h) Zhang, D.X.; Zhang, H.-X.; Wen, T.; Lia, D.-S.; Zhang, J. Mechanochromic Cu(I) boron imidazolate frameworks with lowdimensional structures and reducing function. Inorg. Chem. Front. 2016, 3, 263-267. (i) Lu, T.; Wang, J.-Y.; Tu, D.; Chen, Z.-N.; Chen, X.-T.; Xue, Z.-L. Luminescent Mechanochromic Dinuclear Cu(I) Complexes with Macrocyclic Diamine-Tetracarbene Ligands. Inorg. Chem. 2018, 57, 13618-13630. (j) Feng, N.; Gao, C.; Guo, C.Y.; Chen, G. Copper-Phenylacetylide Nanobelt/Single-Walled Carbon Nanotube Composites: Mechanochromic Luminescence Phenomenon and Thermoelectric Performance. ACS Appl. Mater. Interfaces 2018, 10, 5603-5608. (k) Hupp, B.: Nitsch, J.; Schmitt, T.; Bertermann, R.; Edkins, K.; Hirsch, F.; Fischer, I.; Auth, M.; Sperlich, A.; Steffen, A. Stimulus-Triggered Formation of an Anion-Cation Exciplex in Copper(I) Complexes as a Mechanism for Mechanochromic Phosphorescence. Angew. Chem. Int. Ed. 2018, 57, 13671-13675.

(28) (a) Tran, D.; Bourassa, J. L.; Ford, P. C. Pressure-Induced Luminescence Rigidochromism in the Photophysics of the Cuprous Iodide Cluster $\mathrm{Cu}_{4} \mathrm{I}_{4}$ py. Inorg. Chem. 1997, 36, 439-442. (b) Vogler, A.; Kunkely, H. Photoluminescence of Tetrameric Copper( I) Iodide Complexes in Solution. J. Am. Chem. Soc. 1986, 108, 72117212. (c) Roppolo, I.; Celasco, E.; Sangermano, M.; Garcia, A.; Gacoin, T.; Boilot, J.-P.; Perruchas S. Luminescence variation by rigidity control of acrylic composite materials. J. Mater. Chem. C, 2013, 1 (36), 57255732. 
(29) (a) Zhao, C.-W.; Ma, J.-P.; Liu, Q.-K.; Wang, X.-R.; Liu, Y.; Yang, J.; Yang, J.-S.; Dong Y.-B. An in situ self-assembled $\mathrm{Cu}_{4} \mathrm{I}_{4}$-MOF-based mixed matrix membrane: a highly sensitive and selective naked-eye sensor for gaseous HCl. Chem. Commun., 2016, 52, 5238-5241. (b) Cho, S.; Jeon, Y.; Lee, S.; Kim, J.; Kim, T. H. Reversible Transformation between Cubane and Stairstep $\mathrm{Cu}_{4} \mathrm{I}_{4}$ Clusters Using Heat or Solvent Vapor. Chem. Eur. J. 2015, 21, 1439-1443. (c) Park, H.; Kwon, E.; Chiang, H.; Im, H.; Lee K. Y.; Kim, J.; Kim. T. H. Reversible Crystal Transformations and Luminescence Vapochromism by Fast Guest Exchange in $\mathrm{Cu}(\mathrm{I})$ Coordination Polymers. Inorg. Chem. 2017, 56, 8287-8294. (d) Killarney, J. P.; McKinnon, M.; Murphy, C.; Henline, K. M.; Wang, C.; Pike, R. D.; Patterson, H. H. Amine- and sulfide-sensing copper(I) iodide films. Inorg. Chem. Comm. 2014, 40, 18-21. (e) Benito, Q.; Balogh, C. M.; El Moll, H.; Gacoin, T.; Cordier, M.; Rakhmatullin, A.; Latouche, C.; Martineau-Corcos, C.; Perruchas, S.; Luminescence Vapochromism of a Dynamic Copper Iodide Mesocate. Chem. Eur. J. 2018, 24, 18868-18872.

(30) Liu, W.; Fang, Y.; Wei, J. Z.; Teat, S.J.; Xiong, K.; Hu, Z.; Lustig, W. P.; Li, J.; A Family of Highly Efficient CuI-Based Lighting Phosphors Prepared by a Systematic, Bottom-up Synthetic Approach. J. Am. Chem. Soc. 2015, 137, 9400-9408.

(31) Busch, J. M.; Zink, B. M.; Di Martino-Fumo, P.; Rehak, F. R.; Boden, P.; Steiger, S.; Fuhr, O.; Nieger, M.; Klopper, W.; Gerhards, M.; Bräse, S.; Highly soluble fluorine containing Cu(I) AlkylPyrPhos TADF complexes. Dalton Trans., 2019, 48, 15687-15698.

(32) Jalilian, E.; Liao, R.-Z.; Himo, F.; Brismar, H.; Laurell, F.; Lidin, S.; Luminescence properties of the $\mathrm{Cu}_{4} \mathrm{I}_{6}{ }^{2-}$ cluster. Cryst. Eng. Comm. 13, 2011, 4729-4734.

(33) Liu, W.; Zhu, K.; Teat, S. J.; Dey, G.; Shen, Z.; Wang, L.; O’Carroll, D. M.; Li, J. All-in-One: Achieving Robust, Strongly Luminescent and Highly Dispersible Hybrid Materials by Combining Ionic and Coordinate Bonds in Molecular Crystals. J. Am. Chem. Soc., 2017, 139, 9281-9290.

(34) Jalilian, E.; Lidin, S. Bis(isopropyl-triphenyl-phospho-nium) di- $\mu$-iodido-bis-[iodidocopper(I)]. Acta Cryst. 2010, E66, m432-m433.

(35) Du, H. J.; Liang, Y.; Wang, L. F. ; Niu, Y. Y. Syntheses, Crystal Structures, UV-Vis Absorption, and Fluorescent Properties of a Complex: [btx] $\left[\mathrm{Cu}_{2} \mathrm{I}_{4}\right]$. Synth. React. Inorg. 2012, 42, 364-368.

(36) Liu, Y.-F.; Chen, J.-Z.; Huang, C.-C. Bis\{4-[4-(dimethylamino)styryl]-1-ethylpyridinium $\}$ di-1-iodidobis[iodidocuprate(II)]. Acta Cryst. E63, 2007, m2957-m2962.

(37) Zhang, W.-T. ; Liu, J.-Z. ; Liu, J.-B. ; Song, K.-Y. ; Li, Y. ; Chen, Z.-R. ; Li, H.-H. ; Jiang, R. Quaternary Phosphorus-Induced Iodocuprate(I)-Based Hybrids: Water Stabilities, Tunable Luminescence and Photocurrent Responses. Eur. J. Inorg. Chem. 2018, 4234-4244.

(38) Wu, F.; Tong, H.; Li, Z.; Lei, W.; Liu, L.; Wong, W.-Y.; Wong, W.-K.; Zhu, X. A white phosphorescent coordination polymer with $\mathrm{Cu}_{2} \mathrm{I}_{2}$ alternating units linked by benzo-18-crown-6. Dalton Trans., 2014, 43, 1246312466.

(39) Mishra, S. ; Jeanneau, E. ; Ledoux, G. ; Daniele, S. Novel Barium-Organic Incorporated Iodometalates: Do They Have Template Properties for Constructing Rare Heterotrimetallic Hybrids? Inorg. Chem. 532014 1172111731.

(40) Asplund, M.; Jagner, S. Crystal Structure of Bis(tetrapropylammonium) Di- $\mu$-iodo-diiodoicuprate(I), $\left[\mathrm{N}\left(\mathrm{C}_{3} \mathrm{H}_{7}\right)_{4}\right]_{2}\left[\mathrm{Cu}_{2} \mathrm{I}_{4}\right]$. Acta Chem. Scand. A 38, 1984, 411-421. and references therein

(41) Basu, A.; Bhaduri, S.; Sapre, N.Y.; Jones, P.G. Copper Complexes of 1,1 -Di-2-pyridylethanol: X-Ray Structures and Reaction with Oxygen. J. Chem. Soc., Chem. Commun. 1987 1724-1725.

(42) Cunningham, D.; Gallagher, J.F.; Higgins, T.; McArdle, P.; McGinley, J.; Sheerin, D. A New Co-ordinating Role for a Metal Salicylaldimine. J. Chem. Soc., Chem. Commun. 1990, 959-961.

(43) Bhaduri, S.; Saprea, N.Y.; Jones, P.G. Copper Complexes of I ,I -Di(2 pyridyl)ethyl Methyl Ether:

X-Ray Crystal Structures and Reactions with Dioxygen. J. Chem. Soc., Dalton. Trans. 1991, 2539-2543.

(44) Hoyer, M.; Hartl, H. Iodocuprate(1) mit solvatisierten Kationen: $\left[\mathrm{Li}\left(\mathrm{CH}_{3} \mathrm{CN}\right)_{4}\right] \infty\left[\mathrm{Cu}_{2} \mathrm{I}_{3}\right]$ und $\left[\mathrm{Mg}\left(\left(\mathrm{CH}_{3}\right)_{2} \mathrm{CO}\right)_{6}\right]\left[\mathrm{Cu}_{2} \mathrm{I}_{4}\right]$. Z. Anorg. Allg. Chem. 6121992 45-50.

(45) Ramaprabhu, S.; Ferretti, R.; Lucken, E.A.C.; Bernardinelli, G. NQR studies of polyhalocuprate(I) anions. Inorg. Chim. Acta, 227, 1994, 153-157.

(46) Allen, D. W. ; Mifflin, J. P. L. ; Coles, S. A copper(I)-catalysed template synthesis of solvatochromic arylarsonium and -stibonium systems and a synchrotron structural study of a tetraarylstibonium di-iodocuprate. Chem. Commun. 1998, 2115-2116. 
(47) (a) Su, C.-Y. ; Cai, Y.-P. ; Chen, C.-L. ; Lissner, F. ; Kang, B.-S. ; Kaim, W. Self-Assembly of TrigonalPrismatic Metallocages Encapsulating $\mathrm{BF}_{4}{ }^{-}$or $\mathrm{CuI}_{3}{ }^{2-}$ as Anionic Guests: Structures and Mechanism of Formation. Angew. Chem. Int. Ed. 41, 2002, 3371-3375. (b) Su, C.-Y.; Cai, Y.-P. ; Chen, C.-L. ; Smith, M.D.; Kaim, W.; zur Loye, H.-C. Ligand-Directed Molecular Architectures: Self-Assembly of Two-Dimensional Rectangular Metallacycles and Three-Dimensional Trigonal or Tetragonal Prisms. J. Am. Chem. Soc. 125, 2003, 8595-8613.

(48) Feng, H.; Zhou, X.-P.; Wu, T.; Li, D.; Yin, Y.-G.; Ng, S.W. Hydrothermal synthesis of copper complexes of 40-pyridyl terpyridine: From discrete monomer to zigzag chain polymer. Inorg. Chim. Acta 359, 2006, 4027-4035. (49) Kia, R.; Mirkhani, V.; Harkema, S.; van Hummel, G.J. Synthesis and characterization of the 1:1 adducts of copper(I) halides with bidentate N,NO-bis(benzophenone)-1,2-diiminoethane Schiff base: Crystal structures of $\left[\mathrm{Cu}\left(\mathrm{bz}_{2} \mathrm{en}\right)_{2}\right]\left[\mathrm{CuX}_{2}\right](\mathrm{X}=\mathrm{Br}, \mathrm{I})$ complexes. Inorg. Chim. Acta 3602007 3369-3375.

(50) Hu, G.; Holt, E. M. Tris(trimethylphenylammonium) hexaiodotricuprate(I). Acta Cryst. C, 1994, 50, 15761578.

(51) Herres-Pawlis, S.; Haase, R.; Akin, E.; Flörke, U.; Henkel, G. Syntheses and X-ray Structure Analyses of the First Bis(chelated) Copper and Iron Bisguanidine Complexes. Z. Anorg. Allg. Chem. 2008643 295-298.

(52) Mishra, S.; Jeanneau, E.; Daniele, S. ; Hubert-Pfalzgraf, L.G. Rare example of a polynuclear heterometallic yttrium(III)-copper(I) iodide cluster with a $\left[\mathrm{Y}_{6}\left(\mu_{6}-\mathrm{O}\right)\left(\mu_{3}-\mathrm{OH}\right)_{8}\right]_{8}+$ core structure showing single crystal-to-single crystal transformation. Cryst. Eng. Comm. 102008 814-816.

(53) Liu, B. ; Pan, S. Liu, B. Chen, W. Di-, Tri-, and Tetranuclear Copper(I) Complexes of Phenanthroline-Linked Dicarbene Ligands. Inorg. Chem. 532014 10485-10497.

(54) Zink, D. M. ; Grab, T. ; Baumann, T. ; Nieger, M. ; Barnes, E.C. ; Klopper, W. ; Brase, S. Experimental and Theoretical Study of Novel Luminescent Di-, Tri-,and Tetranuclear Copper Triazole Complexes. Organometallics 302011 3275-3283.

(55) Haase, R.; Beschnitt, T.; Flörke, U.; Herres-Pawlis, S. Bidentate guanidine ligands with ethylene spacer in copper-dioxygen chemistry: Structural characterization of bis(1-hydroxo) dicopper complexes. Inorg. Chim. Acta $2011374546-557$.

(56) Chai, W.-X.; Lin, J.; Song, L.; Qin, L.-S.; Shi, H.-S.; Guo, J.-Y.; Shu, K.-Y. Three iodometalate organicinorganic hybrid materials based on methylene blue cation: Syntheses, structures, properties and DFT calculations. Solid State Sci. 201214 1226-1232.

(57) Haldon, E.; Alvarez, E. ; Nicasio, M.C.; Perez, P.J. Copper(I) Complexes with Trispyrazolylmethane Ligands: Synthesis, Characterization, and Catalytic Activity in Cross-Coupling Reactions. Inorg. Chem. 2012518298 8306.

(58) Ghorai, D.; Mani, G. Single-Step Substitution of all the $\alpha, \beta$-Positions in Pyrrole: Choice of Binuclear versus Multinuclear Complex of the Novel Polydentate Ligand. Inorg. Chem. 201453 4117-4129.

(59) Williams, T.J. ; Bray, J.T.W. ; Lake, B.R.M. ; Willans, C.E. ; Rajabi, N.A. ; Ariafard, A. ; Manzini, C. ; Bellina, F. ; Whitwood, A.C. ; Fairlamb, I.J.S. Mechanistic Elucidation of the Arylation of Non-Spectator NHeterocyclic Carbenes at Copper Using a Combined Experimental and Computational Approach. Organometallics $2015343497-3507$.

(60) Wang, H.; Zhang, J.; Lin, Z.; Xie, Z. Synthesis and Structural Characterization of Carbene-Stabilized Carborane-Fused Azaborolyl Radical Cation and Dicarbollyl-Fused Azaborole. Organometallics 201635 25792582.

(61) Begum, A.; Seewald, O.; Seshadri, T.; Flörke, U.; Henkel, G. Secondary Structures in Inorganic Helicates of an Octadentate Phenanthroline-Type Schiff Base Ligand. Eur. J. Inorg. Chem. 2016 1157-1160.

(62) Mendoza-Espinosa, D.; Alvarez-Hernández, A.; Angeles-Beltrán, D.; Negrón-Silva, G.E.; Suárez-Castillo, O.R.; Vásquez-Pérez, J.M. Bridged N-Heterocyclic/Mesoionic (NHC/MIC) Heterodicarbenes as Ligands for Transition Metal Complexes. Inorg. Chem. 562017 2092-2099.

(63) Artem'ev, A. V.; Pritchina, E. A.; Rakhmanova, M. I.; Gritsan, N. P.; Bagryanskaya, I. Y.; Malysheva, S. F.; Belogorlova, N. A. Alkyl-dependent self-assembly of the first red-emitting zwitterionic $\left\{\mathrm{Cu}_{4} \mathrm{I}_{6}\right\}$ clusters from [alkyl-P(2-Py $\left.)_{3}\right]^{+}$salts and CuI: when size matters. Dalton Trans. 2019, 48, 2328.

(64) Cariati, E. ; Macchi, R. ; Roberto, D. ; Ugo, R. ; Galli, S. ; Masciocchi, N. ; Sironi, A. Sequential SelfOrganization of Silver(I) Layered Materials with Strong SHG by J Aggregation and Intercalation of Organic Nonlinear Optical Chromophores through Mechanochemical Synthesis. Chem. Mater. 19, 2007, 3704-3711. 
(65) Qin, X. ; Zhang, G. ; Gao, Y.; liu, H. ; Du, C. ; Liu, Z. Metallo-supramolecular grid-type architectures for highly and selectively efficient adsorption of dyes in water. RSC Advances, 2015, 5, 43334-43337.

(66) Bowmaker, G. A.; Bruce, M. I.; Skelton, B. W.; Somers, N.; White A. H.; Structural and Spectroscopic Studies of Halocuprate(I) and Haloargentate(I) Complexes $\left[\mathrm{M}_{2} \mathrm{X}_{n} \mathrm{X}_{4-n}\right]^{2-}$. Z. Anorg. Allg. Chem. 2007, 633, 1024-1030.

(67) Hartl, H.; Brüdgam, I.; Mahdjour-Hassan-Abadi, F. Synthese und Strukturuntersuchungen von Iodocupraten(I) VI. Iodocuprate(I) mit zweikernigen Anionen $\left[\mathrm{Cu}_{2} \mathrm{I}_{4}\right]^{2-}$ und $\left[\mathrm{Cu}_{2} \mathrm{I}_{6}\right]^{4-}$. Z. Naturforsch. 1985, 40b, 1032-1039.

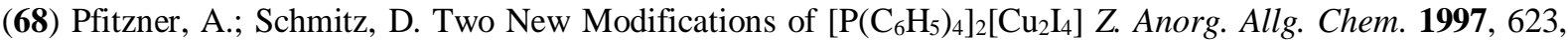
1555-1560.

(69) (a) Bernstein, J. Polymorphism in Molecular Crystals, Clarendon Press Oxford, 2002. (b) Khorloo, M.; Cheng, Y.; Zhang, H.; Chen, M.; Sung, H. H. Y.; Williams, I. D.; Lam, J. W. Y.; Tang, B. Z. Polymorph selectivity of an AIE luminogen under nano-confinement to visualize polymer microstructures. Chem. Sci., 2020, 11, 9971005. (c) Mutai, T.; Satou, H.; Araki K. Reproducible on-off switching of solid-state luminescence by controlling molecular packing through heat-mode interconversion. Nat. Mater. 2005, 4, 685-687. (d) Ito, H.; Muromoto, M.; Kurenuma, S.; Ishizaka, S.; Kitamura, N.; Sato, H.; Seki, T. Mechanical stimulation and solid seeding trigger single-crystal-to-single-crystal molecular domino transformations. Nat. Commun., 2013, 4, 2009-2014. (e) Malwitz, M. A.; Lim, S. H.; White-Morris, R. L.; Pham, D. M.; Olmstead, M. M.; Balch A. L. Crystallization and Interconversions of Vapor-Sensitive, Luminescent Polymorphs of $\left[\left(\mathrm{C}_{6} \mathrm{H}_{11} \mathrm{NC}\right)_{2} \mathrm{AuI}\right]\left(\mathrm{AsF}_{6}\right)$ and $\left[\left(\mathrm{C}_{6} \mathrm{H}_{11} \mathrm{NC}\right)_{2} \mathrm{AuI}\right]\left(\mathrm{PF}_{6}\right)$. J. Am. Chem. Soc. 2012, 134, 10885-10893. (f) Krishnan B. P.; Sureshan, K. M. A Spontaneous Single-Crystal-to-Single-Crystal Polymorphic Transition Involving Major Packing Changes. J. Am. Chem. Soc. 2015, 137, 1692-1696.

(70) Bondi, A. van der Waals volums and radii. J. Phys. Chem. 1964, 68, 441-451.

(71) Sculfort, S.; Braunstein, P. Intramolecular $\mathrm{d}^{10}{ }_{-} \mathrm{d}^{10}$ interactions in heterometallic clusters of the transition metals. Chem. Soc. Rev. 2011, 40, 2741-2760.

(72) Benito, Q.; Baptiste, B.; Polian, A.; Delbes, L.; Martinelli, L.; Gacoin, T.; Boilot, J.-P.; Perruchas, S. Pressure Control of Cuprophilic Interactions in a Luminescent Mechanochromic Copper Cluster. Inorg. Chem. 2015, 54, 9821-9825.

(73) Licari, D. ; Baiardi, A. ; Biczysko, M. ; Egidi, F. ; Latouche, C. ; Barone, V. ; Implementation of a graphical user interface for the virtual multifrequency spectrometer: The VMS-Draw tool, Journal of Computational Chemistry, 2015, 36, 321-334.

(74) Tang, J. A.; Ellis, B. D.; Warren, T. H.; Hanna, J. V.; Macdonald, C. L. B.; Schurko, R. W. Solid-State ${ }^{63} \mathrm{Cu}$ and ${ }^{65} \mathrm{Cu}$ NMR Spectroscopy of Inorganic and Organometallic Copper(I) Complexes. J. Am. Chem. Soc. 2007, 129, 13049-13065.

(75) Benito, Q.; Maurin, I.; Poggi, M.; Martineau-Corcos, C.; Gacoin, T.; Boilot, J.-B.; Perruchas, S. Impact of crystalline packing on the mechanochromic luminescence properties of copper based compounds: towards functional coatings. J. Mater. Chem. C, 2016, 4, 11231-11237.

(76) Benito, Q.; Le Goff, X.; Nocton, G.; Fargues, A.; Garcia, A.; Berhault, A.; Kahlal, S.; Saillard, J.-Y.; Martineau, C.; Trebosc J.; Gacoin, T.; Boilot, J.-P.; Perruchas, S. Geometry Flexibility of Copper Iodide Clusters: Variability in Luminescence Thermochromism. Inorg. Chem. 2015, 54, 4483-4494.

(77) (a) Balch, A. L. Dynamic Crystals: Visually Detected Mechanochemical Changes in the Luminescence of Gold and Other Transition-Metal Complexes. Angew. Chem. Int. Ed. 2009, 48, 2641-2644. (b) Chi, Z.; Zhang, X.; Xu, B.; Zhou, X.; Ma, C.; Zhang, Y.; Liu, S.; Xu, J. Recent advances in organic mechanofluorochromic materials. Chem. Soc. Rev. 2012, 41, 3878-3896. (c) Zhang, X.; Chi, Z.; Zhang, Y.; Liu, S.; Xu, J. Recent advances in mechanochromic luminescent metal complexes. J. Mater. Chem. C, 2013, 1, 3376-3390.

(78) Chen, G.; Zhou, J.; Feng, H.; Feng, F.; Xu, P.; Pan, S.; Xu, J.; Qian, Z. A simple and efficient phosphorescent probe for iodide-specific detection based on crystallization induced phosphorescence of organic ionic crystals. $J$. Mater. Chem. C, 2019, 7, 43-47.

(79) Gaussian 16, Revision A.03, M. J. Frisch, G. W. Trucks, H. B. Schlegel, G. E. Scuseria, M. A. Robb, J. R. Cheeseman, G. Scalmani, V. Barone, G. A. Petersson, H. Nakatsuji, X. Li, M. Caricato, A. V. Marenich, J. Bloino, B. G. Janesko, R. Gomperts, B. Mennucci, H. P. Hratchian, J. V. Ortiz, A. F. Izmaylov, J. L. Sonnenberg, D. Williams-Young, F. Ding, F. Lipparini, F. Egidi, J. Goings, B. Peng, A. Petrone, T. Henderson, D. Ranasinghe, V. G. Zakrzewski, J. Gao, N. Rega, G. Zheng, W. Liang, M. Hada, M. Ehara, K. Toyota, R. Fukuda, J. Hasegawa, M. Ishida, T. Nakajima, Y. Honda, O. Kitao, H. Nakai, T. Vreven, K. Throssell, J. A. Montgomery, Jr., J. E. 
Peralta, F. Ogliaro, M. J. Bearpark, J. J. Heyd, E. N. Brothers, K. N. Kudin, V. N. Staroverov, T. A. Keith, R. Kobayashi, J. Normand, K. Raghavachari, A. P. Rendell, J. C. Burant, S. S. Iyengar, J. Tomasi, M. Cossi, J. M. Millam, M. Klene, C. Adamo, R. Cammi, J. W. Ochterski, R. L. Martin, K. Morokuma, O. Farkas, J. B. Foresman, and D. J. Fox, Gaussian, Inc., Wallingford CT, 2016. Gaussian, Inc.

(80) (a) Perdew, J. P.; Ernzerhof, M.; Burke, K. M. Rationale for Mixing Exact Exchange with Density Functional Approximations. J. Chem. Phys. 1996, 105, 9982-9985. (b) Perdew, J. P.; Burke, K.; Ernzerhof, M. Generalized Gradient Approximation Made Simple. Phys. Rev. Lett. 1996, 77, 3865-3868. (c) Perdew, J. P.; Burke, K.; Ernzerhof, M. Erratum: Generalized Gradient Approximation Made Simple. Phys. Rev. Lett. 1997, 78, 1396-1396. (81) (a) Dunning Jr., T. H.; Hay, P. J. Methods of Electronic Structure Theory, H. F. Schaeffer ed., Plenum Press, New York, 1977. (b) Hay, P. J.; Wadt, W. R. Ab Initio Effective Core Potentials for Molecular Calculations. Potentials for the Transition Metal atoms Sc to Hg. J. Chem. Phys. 198582 270-283. (c) Hay, P. J.; Wadt, W. R. $\mathrm{Ab}$ Initio Effective Core Potentials for Molecular Calculations. Potentials for the Main Group Elements Na to Bi. J. Chem. Phys. 198582 284-298. (d) Hay, P. J.; Wadt, W. R. Ab Initio Effective Core Potentials for Molecular Calculations. Potentials for K to Au Including the Outermost Core Orbitals. J. Chem. Phys. 1985, 82,299-310.

(82) Barone, V.; Baiardi, A.; Bloino, J.; New Developments of a Multifrequency Virtual Spectrometer: StereoElectronic, Dynamical, and Environmental Effects on Chiroptical Spectra, Chirality, 2014, 26, 588-600.

(83) Barone, V.; Baiardi, A.; Biczysko, M. ; Bloino, J. ; Cappellia, C.; Lipparini, P.; Implementation and validation of a multi-purpose virtual spectrometer for large systems in complex environments, Phys. Chem. Chem. Phys., 2012, 14, 12404-12422.

(84) Massuyeau, F.; Faulques, E.; Latouche, C.; New Insights To Simulate the Luminescence Properties of Pt(II) Complexes Using Quantum Calculations, J. Chem. Theory Comput. 2017, 13, 4, 1748-1755.

(85) Li, J.; Wang, J.; Li, H.; Song, N.; Wang, D.; Tang, B. Z. Supramolecular materials based on AIE luminogens (AIEgens): construction and applications. DOI: $10.1039 / \mathrm{c} 9 \operatorname{cs} 00495 \mathrm{e}$ 